\title{
WestVirginiaUniversity
}

THE RESEARCH REPOSITORY @ WVU

Graduate Theses, Dissertations, and Problem Reports

2010

\section{Sex differences in the myocardial response to prenatal and behavioral stress}

Heather Rose Mullenax

West Virginia University

Follow this and additional works at: https://researchrepository.wvu.edu/etd

\section{Recommended Citation}

Mullenax, Heather Rose, "Sex differences in the myocardial response to prenatal and behavioral stress" (2010). Graduate Theses, Dissertations, and Problem Reports. 2969.

https://researchrepository.wvu.edu/etd/2969

This Thesis is protected by copyright and/or related rights. It has been brought to you by the The Research Repository @ WVU with permission from the rights-holder(s). You are free to use this Thesis in any way that is permitted by the copyright and related rights legislation that applies to your use. For other uses you must obtain permission from the rights-holder(s) directly, unless additional rights are indicated by a Creative Commons license in the record and/ or on the work itself. This Thesis has been accepted for inclusion in WVU Graduate Theses, Dissertations, and Problem Reports collection by an authorized administrator of The Research Repository @ WVU. For more information, please contact researchrepository@mail.wvu.edu. 
Sex Differences in the Myocardial Response to Prenatal and Behavioral Stress

Heather Rose Mullenax, B.S.

Thesis submitted to the Davis College of Agriculture, Natural Resources and Design at West Virginia University

in partial fulfillment of the requirements

for the degree of

\title{
Master of Science \\ In \\ Reproductive Physiology
}

\author{
Mitchell S. Finkel, M.D., Chair \\ E.Keith Inskeep, Ph.D. \\ John M. Hollander, Ph.D. \\ Diane B. Miller, Ph.D.
}

Division of Animal and Veterinary Sciences

Morgantown, WV

2010

Keywords: Prenatal Stress, Sex Differences, Heart Function, Proteomics 


\section{Abstract \\ Sex Differences in the Myocardial Response to Prenatal and Behavioral Stress

\author{
Heather Rose Mullenax
}

Prenatal stress (PS) has been shown to exert profound effects on many organs in a variety of species. There is considerable evidence for sex-specific effects of prenatal stress. Our laboratory is the first to report effects of prenatal stress on myocardial function in male rats. The purpose of this study was to confirm our previous evidence of differences in myocardial function among prenatally stressed male and female rats and to explore possible mechanisms responsible for this difference. In this study, male and female Sprague-Dawley rats were subjected to prenatal stress (mother was stressed on day 14-21 of gestation) followed by restraint stress at weeks six and seven of postnatal age (PS+R). Following the second restraint, myocardial function was studied along with a proteomic analysis of the left ventricle. Male PS+R demonstrated both systolic and diastolic dysfunction compared to male Control $+\mathrm{R}$, as evidenced by reduced systolic function $(+\mathrm{dP} / \mathrm{dt})(\mathrm{P}<0.05)$, Left Ventricular Systolic Pressure (LVSP) $(\mathrm{P}<0.05)$, and diastolic function $(-\mathrm{dP} / \mathrm{dt})(\mathrm{P}<0.05)$. There was no significant difference in systolic or diastolic function or left ventricular systolic pressure between female PS+R or female Control $+\mathrm{R}$. There were no significant differences in Mean Arterial Pressure (MAP) or Heart Rate (HR) between PS+R rats of either sex. Proteomic analyses revealed selective up-regulation of 20 mitochondrial proteins and 5 additional stress-related proteins in male PS+R compared to male Control $+\mathrm{R}$. The data also showed an up-regulation of 5 proteins and a down-regulation of 1 protein in female PS+R compared to female Control $+\mathrm{R}$. These findings suggest a sex difference in the oxidative stress response to prenatal stress that may influence myocardial function. Further studies are needed to determine the roles that these differences play in the changes in myocardial function seen in male PS+R vs female PS+R. 


\section{Table of Contents}

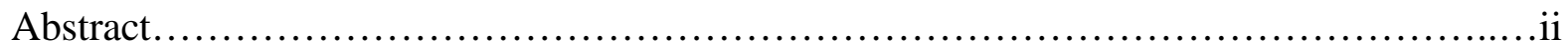

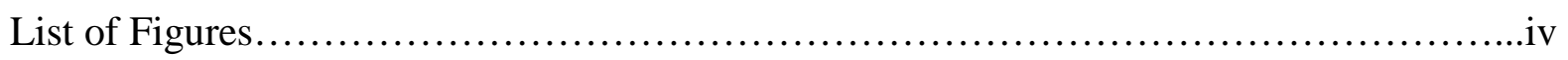

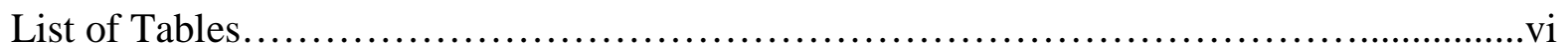

Acknowledgements...........................................................vii

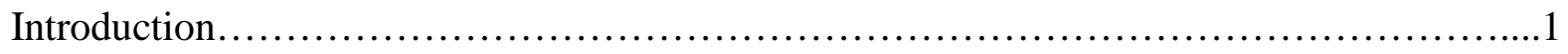

Review of Literature..............................................................

Prenatal Stress............................................................2

Prenatal Stress (PS) Rat Model.............................................

Sex Differences in Prenatal Stress............................................... 5

Reversible Myocardial Dysfunction.........................................

Comparing Myocardial Function in Males and Females..........................8

Prenatal Stress and the Myocardium...................................... 9

Materials and Methods......................................................... 12

Stress Paradigm....................................................... 12

In vivo hemodynamic measurements...................................... 14

Catecholamine Measurements............................................... 14

Proteomics...................................................................

Results........................................................................ 18

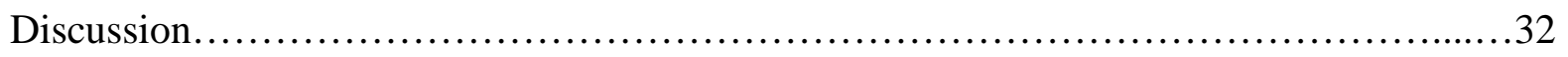

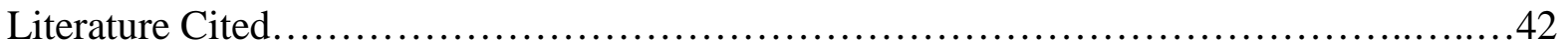




\section{List of Figures}

Figure 1. Representative M-mode echocardiogram of left ventricular (LV) dimensions for Control $+\mathrm{R}$ and PS+R rats. Values are left ventricular end-systolic (2.6 vs 3.5) and end-diastolic (6.5 vs 6.6) dimensions in millimeters 9

Figure 2. . Bar graph depicting the contractile function of adult rat ventricular myocytes isolated from Control $+\mathrm{R}$ and $\mathrm{PS}+\mathrm{R}$ as reflected in $\% \mathrm{FS}$.

Figure 3. Representative tracings of simultaneously recorded LVSP, LVEDP, and positive and negative rates of change in left ventricular pressure over time $(+\mathrm{dP} / \mathrm{d} t$, $-\mathrm{dP} / \mathrm{d} t)$ in a freely ambulatory, awake rat from the PS+R group.......................10

Figure 4. Preliminary study showing differences in systolic function in PS+R males.......11

Figure 5. Preliminary study showing differences in diastolic function in PS+R males......11

Figure 6. Flow diagram illustrating the steps involved in generating this animal model of stress-induced myocardial "stunning."

Figure 7. Bar graph depicting differences in hemodynamic responses between male vs. female rats after PS+R. PS+R males demonstrated decreased systolic contractility compared with Control $+R$ males $(\mathrm{p}<.05)$. Systolic function was not significantly different between $P S+R$ and

Control $+\mathrm{R}$ females 20

Figure 8. Bar graph depicting differences in hemodynamic responses between male vs. female rats after PS+R. Diastolic dysfunction was significantly greater in male PS+R vs. male Control + $\mathrm{R}$ (Control $+\mathrm{R}$ vs. PS $+\mathrm{R}, * \mathrm{P}<0.05$ ). No differences between age-matched female $\mathrm{PS}+\mathrm{R}$ and female Control $+\mathrm{R}$ were observed. .21

Figure 9. Bar graph depicting differences in left ventricular systolic pressure (LVSP) between male vs. female rats after PS+R. LVSP was significantly lower in male PS+R vs. male Control + $R$. No differences between age-matched female PS $+R$ and female Control $+R$ were observed. .22

Figure 10. Bar graph depicting Mean Arterial Pressure (MAP) in male PS+R and Control $+\mathrm{R}$ and female $\mathrm{PS}+\mathrm{R}$ and Control $+\mathrm{R}$ rats.

Figure 11. Bar graph depicting no differences in Heart Rate (HR) between male PS+R and male Control $+\mathrm{R}$ or between female $\mathrm{PS}+\mathrm{R}$ and female Control $+\mathrm{R}$..... .24

Figure 12. MS/MS spectrum depicting ATP Synthase Alpha subunit peptide that was upregulated in male PS+R (115) vs. male Control +R (117). There was no difference in expression

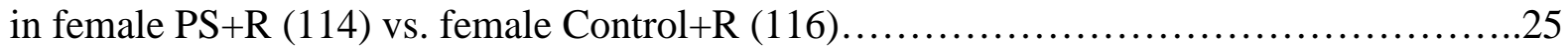


Figure 13. MS/MS spectrum depicting Cytochrome c oxidase subunit 4 peptide that was upregulated in male PS+R (115) vs. male Control $+\mathrm{R}$ (117). There was no difference in expression in female PS+R (114) vs. female Control +R (116) ...................................26

Figure 14. MS/MS spectrum depicting Sodium/potassium-transporting ATPase subunit alpha-1 peptide that is down-regulated in female PS $+\mathrm{R}(114)$ vs. female Control $+\mathrm{R}$ (116). There was no difference in expression between male PS+R (115) and male Control +R (117) .............27 


\section{List of Tables}

Table 1. List of proteins that were up-regulated in male PS+R vs male Control +R......28

Table 2. List of proteins that were up-regulated or down-regulated in female PS+R vs. female

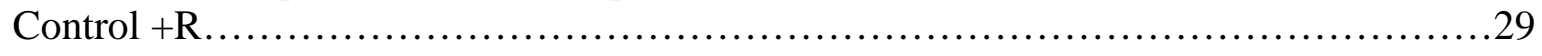

Table 3. Norepinephrine measurements showing significant differences between male PS $+\mathrm{R}$ and male Control $+\mathrm{R}$ and female $\mathrm{PS}+\mathrm{R}$ and female Control $+\mathrm{R}(\mathrm{P}$ value $=0.0112) \ldots \ldots \ldots . .30$

Table 4. Epinephrine measurements showing significant differences between male $\mathrm{PS}+\mathrm{R}$ and male Control $+\mathrm{R}$ and female $\mathrm{PS}+\mathrm{R}$ and female Control $+\mathrm{R}(\mathrm{P}$ value $=0.0029) \ldots \ldots \ldots \ldots 31$ 


\section{Acknowledgements}

I would like to thank all of my committee members for their contributions and insights into this project. Thanks to my major advisor, Dr. Finkel, who provided me with the guidance and means to carry out this study. Without him, this would not have been possible. Also, a special thanks to Dr. Inskeep for his guidance; not only with this project, but also other aspects of my academic career. Thanks to Dr. Hollander for advice on the proteomics, and Dr. Miller for designing and coordinating catecholamine assays. Also, thanks to Fangping Chen, $\mathrm{PhD}$, without whom, the hemodynamic data could not have been collected. I would also like to thank my fellow graduate students for their friendship and guidance through the "unknown" aspects of academia. Finally, I would like to thank my family. Mom and Dad, I could not have completed this degree or any of my other college experiences without your support and your undying faith in me. 


\section{Introduction}

Prenatal stress (PS) during the last third of pregnancy has been defined as "stress experienced by the pregnant mother which affects the development of the offspring.” Studies have demonstrated that there are sexual differences in response to prenatal stress in behavior, brain development, and other organs of the body. Birkle developed a model to study the effects of behavioral stress on the developing, juvenile and adult brain using PS rats. Her data have shown that stressing pregnant rats with handling, daily saline injection and exposure to a novel environment during the last week of gestation (G14-G21) produced offspring (PS) that were more susceptible to the behavioral and neuroendocrine effects of stress. These offspring had enlarged adrenal glands, elevated corticotropin releasing factor (CRF), elevated circulating corticosterone levels, increased heart rates, decreased body weights, and enlarged brain amygdalae (site of emotional responses to stress) compared with offspring of non-stressed dams. Behaviorally, Birkle's prenatal stress model resulted in offspring that were hyper-responsive to anxiety-provoking stimuli (e.g. increased defensive withdrawal in a novel environment and following restraint stress), an essential characteristic of the prenatal stress syndrome. Previous studies in our laboratory using the Birkle model have shown that prenatal stress can influence myocardial function in response to restraint stress. The following literature review focuses on defining prenatal stress, how prenatal stress affects different systems in the body, sex differences in prenatal stress, and the role that prenatal stress plays in myocardial function. 


\section{Review of Literature}

\section{Prenatal Stress}

Prenatal stress during the last third of pregnancy has been defined as "stress experienced by the pregnant mother which affects the development of the offspring” (Braastad, 1998). Extensive studies focused on rodents and primates have concluded that prenatal stress may affect the offspring of stressed mothers. Other research indicates species other than rodents and primates may exhibit similar effects of prenatal stress, as well. The primary focus of those studies was to extrapolate these data into human situations and to develop a better understanding of maternal influences that may affect the development of offspring of livestock species.

Multiple rodent and primate studies strongly indicate the presence of impairment in stress-coping abilities and social conflict behavior in both juvenile and adult offspring of prenatally stressed mothers. The offspring of prenatally stressed females show retarded motor development, reduced exploratory and play behavior, learning ability impairments, and impaired social behavior which may include impaired sexual and maternal behavior. In some cases, sexratio and reproductive success of these offspring also may be influenced. (Braastad, 1998)

Various stressors have been used in developing models for prenatal stress. These stressors include crowded conditions, unstable social conditions, handling by humans, avoidance tests, REM sleep deprivation, uncontrollable and unpredictable electric shocks, flood lights, flashing lights and ringing bells, restraint, heat and restraint, saline injections, or food restrictions. These stressors may be used alone or in combination (Braastad, 1998). 
In many prenatal stress studies, daily use of stressors was utilized during the last third of pregnancy (last trimester for humans). However, some studies indicate that the timing of specific stressors administered during pregnancy may manifest different consequences. Thus, the specific nature of the prenatal stress and the time at which the dams experience that stress, may influence the effects of prenatal stress on their offspring. Reduced gonadal weight, reduced anogenital distance in males, and a depressed immune function are common examples of prenatal stress on offspring. Many other adverse consequences may result from prenatal stress.

Mulder et al. (2002) looked at prenatal maternal stress and its effect on pregnancy and the unborn child. Animal experiments revealed that prenatal stress affected pregnancy outcomes and resulted in early programming of brain functions, including permanent changes in neuroendocrine regulation and behavior in offspring. Well-controlled human studies indicated that pregnant women with high stress and anxiety levels are at an increased risk of abortion and preterm labor. Mulder et al (2002) concluded from their review that maternal psychological factors may greatly contribute to pregnancy complications and abnormal development of the unborn child.

\section{Prenatal Stress (PS) Rat Model}

The prenatally stressed rat has gained widespread acceptance as an animal model for mood disorders. Offspring of rats that are subjected to behavioral stress during pregnancy show behavioral disturbances indicative of increased fearfulness. PS rats enter the "safer", closed arms of the elevated plus maze more frequently then the offspring of unstressed dams and display hyperactivity in a familiar open field (Fride, 1988, Weinstock, 1988). PS rats also freeze longer in response to foot shock, and fail to exhibit foot shock-induced analgesia (the absence of the 
sense of pain) (Takahashi , 1988, Takahashi, 1990). Acquisition of the two-way active avoidance task is impaired in PS rats, and they demonstrate accelerated punished extinction of a running response (Fride, 1986). Various modifications of the PS rat paradigm have been developed using different specific stressors (Weinstock, 1998). A common feature of these PS variants is enhanced sympatho-adrenal activation in response to stressful stimuli (Weinstock, 1998).

One model that was developed to study the effects of environmental stress on the developing, juvenile and adult brain using PS rats was adapted for this study (Cratty, 1995). This model has shown that stressing pregnant rats with handling, daily saline injection and exposure to a novel environment during the last week of gestation (G14-G21) produces offspring that are more susceptible to the behavioral and neuroendocrine effects of stress. These offspring have increased defensive withdrawal in a novel environment and following restraint stress, adrenal hypertrophy and increased plasma corticosterone levels. In addition, these PS offspring have elevated concentrations of the anxiogenic neuropeptide, CRF, as early as postnatal day 1 (P1) in the hypothalamus, and by postnatal day 14 (P14) in the amygdala. Although various maternal stress protocols have been used to produce prenatal stress, the critical variables appear to be the nature of the maternal stressor, the timing during gestation, and whether maternal adaptation occurs before crucial periods of embryonic development (Weinstock, 1997). The prenatal stress model used in this study results in offspring that are hyper-responsive to anxietyprovoking stimuli (i.e. hyperemotional) which is the essential characteristic of the prenatal stress syndrome. 


\section{$\underline{\text { Sex Differences in Response to Prenatal Stress }}$}

The impact of the sex of the offspring on manifestations of prenatal stress are detailed in research by Lay et al. (2008). In this study, pregnant porcine sows were exposed to prenatal stress by rough handling during pregnancy. Another group of sows was injected with adrenocorticotropic hormone (ACTH). This hormone is released when animals are under conditions of stress. Elevated stress levels equates to higher ACTH levels. The anogenital distance (distance from anus to genitals) was measured and pigs born to ACTH-injected sows had a smaller anogenital distance when compared to controls. Offspring from the rough handled sows were intermediate to the ACTH-injected groups and the control groups. This observation demonstrates a feminization of male offspring of prenatally stressed sows.

Bowman et. al. (2004) looked at differences in the effects of prenatal stress on cognition, hormonal responses, and central neurotransmitters in male and female rats. Pregnant dams were subjected to restraint stress three times a day for 45 minutes per restraint during d 14-21 of pregnancy. Control and prenatally stressed offspring were evaluated for anxiety related and cognitive behaviors, stress and gonadal steroid hormone concentrations, and monoamines and metabolite concentrations in selected brain regions. The results of this study showed an attenuation of serum corticosterone response to stress in prenatally stressed females which eliminated the sex difference normally observed. Higher anxiety levels were exhibited by prenatally stressed females when they took longer to enter an open field. Prenatally stressed males showed a decrease in performance of a spatial memory task. When looking at neurochemical profiles of prenatally stressed females, they were altered toward the masculine phenotype in the prefrontal cortex, amygdale, and hippocampus. From this, they concluded that 
prenatal stress affects multiple aspects of brain development by interfering with normal behavior, neuroendocrine, and neurochemical sex differences.

Prenatal stress and postnatal development of neonatal rats have been studied by Nishieo et al. (2001). They looked at sex-dependent effects on emotional behavior and learning ability of neonatal rats. Their prenatal stress paradigm consisted of maternal sound stress combined with forced swimming stress for 15 minutes per day. This involved noise at $800 \mathrm{~Hz}, 77 \mathrm{~dB}$, every other minute for 15 minutes per day during d 10-18 of gestation. At 4 weeks of age, male offspring showed a sound-induced reduction of locomotor activity that was not seen in female offspring of the same age. When exposed to a water-maze test at 6 weeks of age, there was an increase in the total number of errors by males when compared to females. They concluded that prenatal stress may have sex-dependent effects on emotional behavior and learning ability of neonatal rats.

McCormick et al. (1995) looked at the sex-specific effects of prenatal stress on hypothalamic-pituitary-adrenal responses to stress and brain glucocorticoid receptor density in adult rats. Dams were placed in wire-mesh restrainers in the afternoon for twenty minutes on days fifteen through nineteen, post conception. At five months of age, offspring were restrained. They measured adrenocorticotropin and corticosterone concentrations of offspring from prenatally stressed dams at $0,20,40$, and 70 minutes following restraint stress. Female offspring of the prenatally stressed dams had higher plasma ACTH and corticosterone levels in response to restraint. Males were not affected. This observation demonstrates a greater effect of prenatal stress on hypothalamic-pituitary-adrenal function in females compared to males.

A pronounced effect on females but not on males is not always the case. Prenatal stress may affect brain development and behavior differently depending on the sex of the offspring. 
Weinstock (2007) reported that prenatal stress increased corticosterone concentrations in the fetal brain and decreased fetal testosterone and brain aromatase activity in males. This decrease in fetal testosterone and brain aromatase activity could be a possible explanation for the decreased anogential distance in the male pigs (Lay et. al. 2008). Weinstock (2007) also saw learning deficiencies, reductions in hippocampal neurogenesis, long-term potentiation (LTP) and dendritic spine density in the prefrontal cortex of prenatally-stressed males. When looking at the prenatally-stressed females, there was altered brain catecholamine activity, an increase in anxiety and depression, and an increased hypothalamic-pituitary-adrenal response to stress.

These studies by Lay et al. (2008) and McCormick (2007) demonstrated a sexual difference in response to prenatal stress for brain development and behavior along with hormone release. There is limited research on the effect of prenatal stress on specific organs in the body. My research focused on prenatal stress combined with behavioral stress and the impact these stresses have on the offspring's heart.

\section{$\underline{\text { Reversible Myocardial Dysfunction }}$}

Myocardial ischemia followed by reperfusion was first shown to be associated with a transient period of depressed contractility in the opened chest dog model (Heyndrickx, 1975). This transient, reversible episode of depressed contractility was defined as a period of myocardial stunning, or "stunned myocardium”. The clinical implications of these experimental observations were not fully appreciated until sophisticated imaging techniques enabled clinicians to assess myocardial contractility and viability non-invasively in patients (Braunwald, 1982). It has become increasingly apparent that a number of clinical conditions result in reversible 
depression of myocardial contractility. Clinically, this condition has been seen in patients following myocardial infarction, cardiopulmonary bypass, thrombolytic therapy, and coronary angioplasty. Women who are post menopausal are more likely to present with cases of stunned myocardium following an emotionally traumatic experience. This raises the question, "What difference in male and female stress response could explain this difference in myocardial function?”

\section{Comparing Myocardial Function in Males and Females}

There is a scarcity of literature published comparing myocardial function in males and females. Schaible (1984) reported that when rats were age matched at 18 weeks of age, coronary flow and end diastolic volume were the same in male and female hearts. However, stroke work, ejection fraction and fractional shortening were significantly greater in male hearts when compared to female hearts, but only when there was increase in ADP. In a second experiment, they matched heart mass instead of age. This study resulted in findings that show a greater coronary flow, end diastolic volume, stroke work, ejection fraction, and fractional shortening in male rats compared to females with the same heart mass. These results show that intrinsic cardiac function is greater in male rats compared to female rats.

Another study performed by Adams et al. (1999) looked at gender differences in survival with advanced heart failure. The patients that they enrolled in the study consisted of 359 men and 112 women who had evidence of end-stage heart failure with marked symptoms and severe left ventricular dysfunction. They concluded that women with advanced heart failure appear to have better survival rates than men. 


\section{Prenatal Stress and the Myocardium}

Our laboratory adopted the Birkle prenatal stress model to explore the effects of prenatal stress on the myocardium (Kan et. al. 2005). The prenatally stressed mother was stressed by handling, saline injection, and relocation to a new cage during the last week of her three-week pregnancy. The control mother was not subjected to any of these stressors throughout gestation. At six and seven weeks of age, male offspring from prenatally stressed dams (PS) and control dams (Control) were restrained for two hours (PS+R; Control +R). Echocardiograms were performed the day after the last restraint stress. The PS+R males compared with Control $+\mathrm{R}$ males showed a decrease in percent fractional shortening (a measure of left ventricular function) and an increase in systolic dimensions, while there was little change in diastolic dimensions (Fig 1 and 2). There were no echocardiographic differences between the Control alone, PS alone or Control $+\mathrm{R}$. Thus, PS alone is not sufficient to demonstrate echocardiographic abnormalities. However, the combination of prenatal stress plus subsequent behavioral restraint stress does demonstrate echocardiographic evidence of myocardial dysfunction.

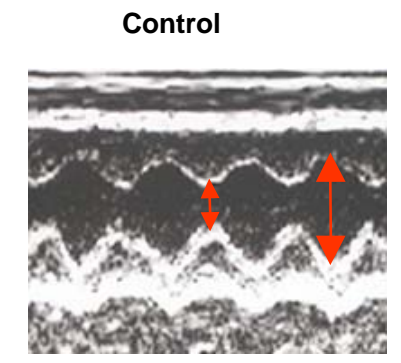

2.6
6.5

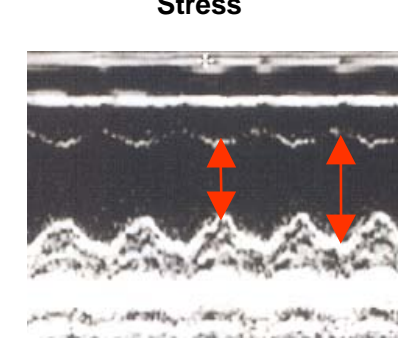

3.5

6.6

Figure 1. Representative M-mode echocardiogram of left ventricular ( $\mathrm{LV}$ ) dimensions for Control $+\mathrm{R}$ and PS+R rats. Values are left ventricular end-systolic (2.6 vs 3.5) and end-diastolic (6.5 vs 6.6) dimensions in millimeters.

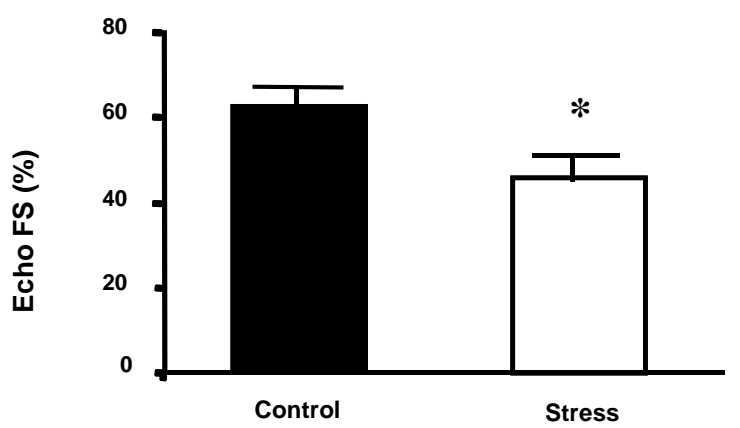

Figure 2. Bar graph depicting the contractile function of adult rat ventricular myocytes isolated from Control $+\mathrm{R}$ and $\mathrm{PS}+\mathrm{R}$ as reflected in \%FS. 
Echocardiography in patients is considered "non-invasive” because no drugs or trauma are required. However, echocardiography in animal models requires general anesthesia. Accordingly, our laboratory acquired a technique that allowed hemodynamic monitoring in awake rats following initial insertion of catheters under general anesthesia. The use of the more sensitive catheter-based technique also provided convincing data on diastolic function, as reflected in -dp/dt. More importantly, this catheter-based technique provided the unique capacity to assess hemodynamic parameters in the more physiologically and clinically relevant conditions of freely ambulatory and awake animals Accordingly, left ventricular end-systolic pressure, enddiastolic pressure, heart rate, and blood pressure were measured in these male rats under anesthesia and awake (Figure 3). Left ventricular end-systolic pressure and blood pressure decreased in stressed rats (PS+R), under anesthesia, with no significant difference in left ventricular end-diastolic pressure or heart rate. When awake, prenatally stressed male rats (PS+R) had a greater, decrease in left ventricular end-systolic pressure with no significant difference in left ventricular end-diastolic pressure, heart rate, or blood pressure.

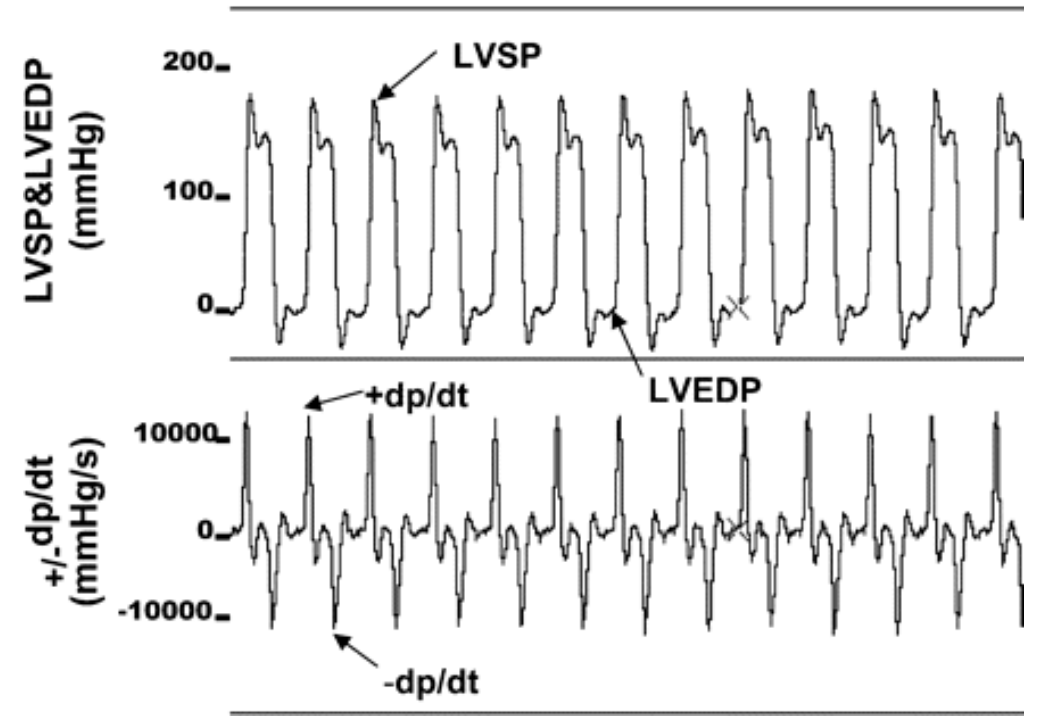

Figure 3.Representative tracings of simultaneously recorded LVSP, LVEDP, and positive and negative rats of change in left ventricular pressure over time $(+\mathrm{dP} / \mathrm{d} t$, $-\mathrm{dP} / \mathrm{d} t$ ) in a freely ambulatory, awake rat from the PS+R group. 
There were no significant differences in systolic (+dp/dt) or diastolic (-dp/dt) function between male and female Control (Control $+\mathrm{R})$, or female Stress (Stress $+\mathrm{R})$. Only prenatally stressed males (PS+R) developed significant decreases in both systolic and diastolic function (Fig. 4 and 5). Prenatally stressed female rats subjected to repeated restraint stress retained the same systolic and diastolic function as their female or male controls. The data reported for male and female differences showed that prenatal stress did not have the same effect on myocardial function in females as it did in males. This difference was noted for both left ventricular end-systolic and end-diastolic function.

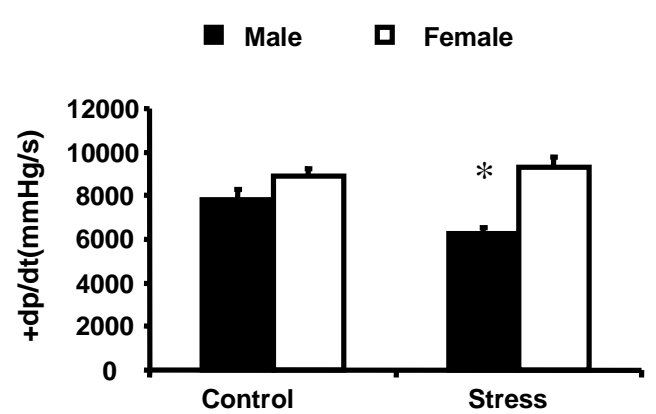

Figure 4. Preliminary studies showed a significant decrease in systolic pressure in male PS+R compared to female PS+R.

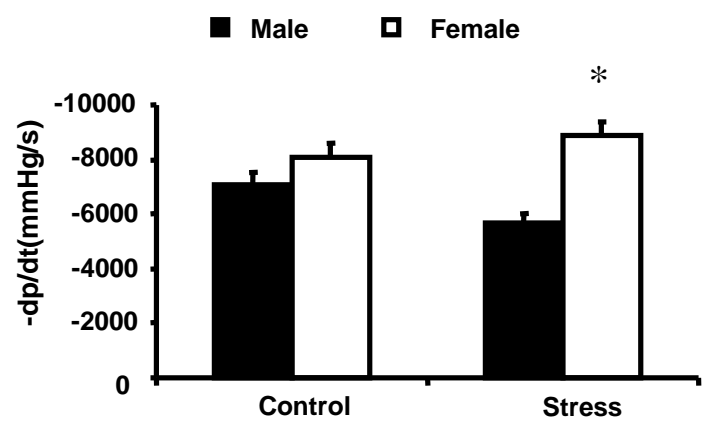

Figure 5. Preliminary studies showed a significant decrease in diastolic pressure in male PS $+\mathrm{R}$ compared to female PS $+\mathrm{R}$. 


\section{Materials and Methods}

Stress Paradigm: Virgin male and female Sprague Dawley rats were purchased from Hilltop Lab Animals, Inc. These animals were then housed in the CDC/NIOSH animal quarters. After a week of acclimation time, male and female rats were paired. After presence of a vaginal plug, the animals were separated. Control dams were left undisturbed throughout gestation. After parturition, dam and pups were left undisturbed until weaning. Stressed dams were left undisturbed for the first two weeks of gestation. During the third week (days 14 to day 21), the dam was removed from her cage, received a saline injection in the folds of skin on the back of the neck, and was placed in a new cage and moved to a new location on the cage rack. After parturition, the dam and pups were left undisturbed until weaning. At weaning, all pups (control and stressed) were weaned and placed in cages in groups of 2 to 3 pups per cage. At 6 and 7 weeks of age, each control or stress pup was placed in a clear, plastic restrainer for two hours (a total of 4 hours of restraint for each rat during the whole procedure) (Fig. 6). During restraint the animal's head was exposed but it was unable to back up or turn and had limited lateral mobility. The day after the 7 week old restraint, the pups were then transported from the CDC/NIOSH animal quarters to the Health Science Center loading dock. From there, they were transported to the lab for the experimental procedures. 
Control

象우

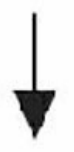

우

Pregnant

No maternal stress

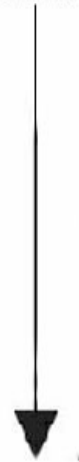

offspring

Post-natal day 42

Restraint(2hrs)

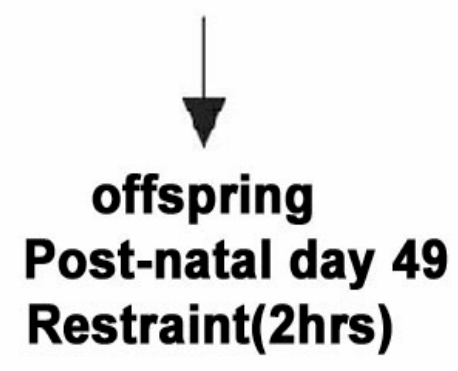

Stress

$\hat{0}+$ 우

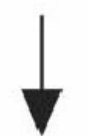

9

Pregnant

Maternal stress

Third trimester

Gestational days 14-21

Daily saline injection Novel environment

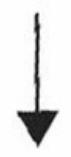

offspring

Post-natal day 42

Restraint(2hrs)

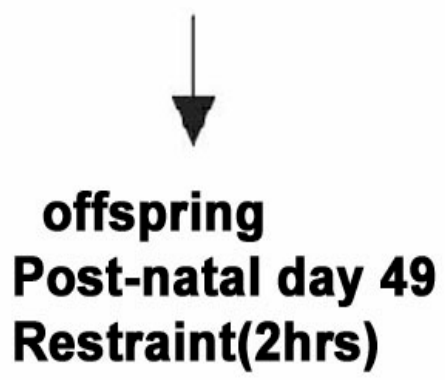

Figure 6. Flow diagram illustrating the steps involved in generating this animal model of stress-induced myocardial "stunning." 
In vivo hemodynamic measurements: For in vivo hemodynamic measurements, catheters were inserted into rats under anesthesia with $2 \%$ isoflurane at the rate of $2 \mathrm{l} / \mathrm{min}$ oxygen. Catheters were passed through subcutaneous tunnels at the back of the neck and patency was maintained with heparin flushes. Initial hemodynamic determinations were made while the animals were still under general anesthesia (“anesthetized”). "Awake” measurements were made at 2 hours after anesthesia, when all rats were fully conscious and freely ambulatory. For intravenous drug administration, a silicone catheter was placed in the right jugular vein. Mean arterial pressure was measured with a catheter inserted into the left femoral artery which was then passed through subcutaneous tunnels to the back of the neck. A catheter that was advanced into the left ventricle via a right carotid artery or a femoral artery catheter determined left ventricular systolic pressure (LVSP), positive and negative rates of change in left ventricular pressure over time $(+\mathrm{dp} / \mathrm{dt}$ and $\mathrm{dp} / \mathrm{dt}$ ), systemic blood pressure, and heart rate measurements.

Catecholamine Measurements. A blood sample of $900 \mu \mathrm{l}$ was collected in microfuge tube with $100 \mu \mathrm{l}$ of $30 \%$ sodium citrate after rats were anesthetized by pentobarbital ( $50 \mathrm{mg} / \mathrm{kg}$ ). The blood sample was centrifuged at $1,000 \times \mathrm{g}$ for $10 \mathrm{~min}$ at $4^{\circ} \mathrm{C}$. The plasma was transferred to a new centrifuge tube and stored at $-70^{\circ} \mathrm{C}$ for analysis. Plasma norepinephrine (NE) and epinephrine (EP) were extracted with ESA plasma catecholamine kit (ESA, Inc., Chelmsford, MA 01824, USA) according to the manufacturer's instruction. Separation and quantitation of NE and EP was accomplished by HPLC with electrochemical detection (Coulochem II, ESA, Inc., Chelmsford, MA 01824, USA), the column used was an ESA HR-80 (80 x $4.6 \mathrm{~mm})$ with the potential conditions, $200 \mathrm{mV}$ for the conditioning cell, $100 \mathrm{mV}$ for $\mathrm{E} 1 \mathrm{and}-100 \mathrm{mV}$ for E2. The mobile phase (ESA, CAT-A-Phase II) flow was at $1.2 \mathrm{ml} / \mathrm{min}$. Data were analyzed by Waters 
Millennium 32 software and enabled accurate determination of pg of noradrenaline and adrenaline.

Proteomics Project: The procedures for the proteomics analysis were provided by Protea Biosciences, Inc.

\section{Sample Description:}

A total of 4 samples was submitted for iTRAQ relative protein quantitation.

Table 1 summarizes the client sample information:

\begin{tabular}{|c|c|c|c|}
\hline Sample ID & Quantity/ $\mathbf{\mu g}$ & $\begin{array}{c}\text { Species } \\
\text { (if known) }\end{array}$ & info \\
\hline 1 & $1.5 \mathrm{mg} / 1500 \mu \mathrm{L}$ & Rat & Control Male - label 117 \\
\hline 2 & $1.5 \mathrm{mg} / 750 \mu \mathrm{L}$ & Rat & Stress Male - label 115 \\
\hline 3 & $1.5 \mathrm{mg} / 750 \mu \mathrm{L}$ & Rat & Control Female - label 116 \\
\hline 4 & $1.5 \mathrm{mg} / 750 \mu \mathrm{L}$ & Rat & Stress Female - label 114 \\
\hline
\end{tabular}

\section{Project Goal:}

To perform relative protein quantitation of proteins present in four samples using iTRAQ labeling, LC-MALDI TOF-TOF MS/MS mass spectrometry, and ProteinPilot 3.0 software.

\section{Experimental:}

a. Sample preparation - protein digestion and ITRAQ labeling

i. A volume of $100 \mathrm{uL}$ of each sample was mixed with $600 \mu \mathrm{L}$ of acetone, and precipitated overnight at $-20^{\circ} \mathrm{C}$.

ii. The resulting pellet was reconstituted in $160 \mu \mathrm{L}$ of dissolution buffer, and $8 \mu \mathrm{L}$ of denaturant from the iTRAQ kit.

iii. An aliquot of $16 \mu \mathrm{L}$ of reducing agent was added, and the samples incubated at $60{ }^{\circ} \mathrm{C}$ for $60 \mathrm{~min}$, after which $8 \mu \mathrm{L}$ of cysteine blocking reagent was added and incubated for $10 \mathrm{~min}$ at room temperature in the dark.

iv. Proteolytic digestion was performed by adding $2 \mu \mathrm{g}$ of trypsin, and the samples were incubated overnight at $37^{\circ} \mathrm{C}$.

v. After digestion, the samples 1, 2, 3 and 4 were labeled with iTRAQ reagents $117,115,116$ and 114 respectively, by transferring the 
contents of the ITRAQ vial into the sample solutions. The ITRAQ reagents were reconstituted with $50 \mu \mathrm{L}$ of ethanol and two vials of each label were used per samples. The samples were incubated at room temperature for $60 \mathrm{~min}$.

vi. A further $100 \mu \mathrm{L}$ of deionized water was added, and the samples were incubated for $30 \mathrm{~min}$ at room temperature to stop the reaction.

vii. The samples were then combined, frozen and lyophilized for reconstitution into SCX reconstitution buffer.

b. SCX Fractionation

i. The samples were fractionated using SCX ProteaTip SpinTips.

ii. The tips were first washed to wet the packing material by adding 50 $\mu \mathrm{L}$ of SCX loading buffer and centrifuging the system at $4000 \mathrm{rpm}$ for 2 min.

iii. The sample was then loaded in the spin tip and centrifuged at 4000rpm for 2 min after which it was washed to elute salts and other non-retained components by adding $50 \mu \mathrm{L}$ of the rinse solution ( $5 \mathrm{mM}$ ammonium formate in $10 \%$ acetonitrile) to the top of the SpinTip.

iv. The SpinTip was transferred to a new clean centrifuge tube to collect the sample during elution with $150 \mu \mathrm{L}$ of elution solution. Eight different elution solutions were used fractionate the peptides and were 20, 40,60, 80, 100, 150, 250, $500 \mathrm{mM}$ ammonium formate in $10 \%$ acetonitrile.

v. The collected fractions were cleaned by repeated lyophilizing and reconstituting in a $0.1 \mathrm{M}$ acetic acid solution. After final lyophilization, the digests were reconstituted in LC run buffer.

c. LC-MALDI spotting

Instrument: ABI Tempo LC MALDI

Data acquisition and processing program: Tempo LC MALDI v.2.00.09

1) Lyophilized digested samples were reconstituted in $12 \mu \mathrm{L}$ of $0.1 \%$ TFA in D.I water

2) Injection volume - $10 \mu \mathrm{L}$

3) Separation column - Merck Chromolith CapRod monolith column - 150 $\times 0.1 \mathrm{~mm}$

4) Separation Gradient (30 minute gradient)

5) Table 1. LC-MALDI spotting gradient program.

\begin{tabular}{|c|c|c|}
\hline Time I $\mathbf{m i n}$ & $\begin{array}{c}\text { \% A (0.1\% acetic } \\
\text { acid } \mathbf{2} \% \\
\text { acetonitrile) }\end{array}$ & $\begin{array}{c}\text { \% B (0.1 \% acetic } \\
\text { acid in } \mathbf{9 0 \%} \\
\text { acetonitrile) }\end{array}$ \\
\hline 0 & 97 & 3 \\
\hline 5 & 97 & 3 \\
\hline 15 & 60 & 40 \\
\hline
\end{tabular}




\begin{tabular}{|c|c|c|}
\hline 18 & 20 & 80 \\
\hline 20 & 20 & 80 \\
\hline 21 & 97 & 3 \\
\hline 25 & 97 & 3 \\
\hline
\end{tabular}

d. MALDI mass spectrometer parameters Instrument: $A B I 4800$ MALDI TOF/TOF analyzer

Data acquisition and processing program: 4000 Series Explorer software

MS acquisition in reflector mode positive ion mode

Mass range $=\mathrm{m} / \mathrm{z}=850-4000$

400 laser shots per spectrum

Minimum S/N = 10 for MS acquisition

15 strongest precursors chosen for MS/MS

Minimum S/N = 30 for MSMS precursors

MALDI spot interrogated until at least 4 peaks in the MSMS spectra achieved a $\mathrm{S} / \mathrm{N}=70$

e. Database correlation analysis search parameters

i. Protein identification from MS/MS data

Program for MS/MS data processing: ABI Protein ProteinPilot software 3.0

Search Engine: Paragon

Sample Type: iTRAQ 4plex (peptide labeled)

Digestion Enzyme: Trypsin

Special Factors: none

Species: Rat

I.D Focus: Biological modifications

Database: NCBInr

False Discovery Rate: $1 \%$ 


\section{Results}

The catheter-based technique provided the unique capacity to assess hemodynamic parameters in the most physiologically and clinically relevant awake state. The male PS+R animals demonstrated both systolic and diastolic dysfunction compared to male Control $+\mathrm{R}$, as evidenced by reduced $+d \mathrm{P} / \mathrm{dt}(\mathrm{P}<0.05)$, LVSP $(\mathrm{P}<0.05)$, and $-\mathrm{dP} / \mathrm{dt}(\mathrm{P}<0.05)$. There were no significant differences in systolic or diastolic function or left ventricular systolic pressure between female PS+R or female Control +R (Fig. 7, 8, and 9). There was no significant difference in Mean Arterial Pressure (MAP) among male PS+R and male Control +R or female PS + R and female Control +R (Fig. 10). There was also no significant difference in Heart Rate (HR) among groups (Fig. 11).

Proteomic analysis revealed selective increases in mitochondrial proteins in male PS $+\mathrm{R}$ compared to male Control +R including, up-regulation of ATP synthase alpha subunit peptide. However, there was no significant difference in expression of that protein between female PS+R and female Control $+\mathrm{R}$ (Fig. 12). There was also up-regulation of Cytochrome C oxidase subunit 4 peptide in male $\mathrm{PS}+\mathrm{R}$ compared to male Control $+\mathrm{R}$ with no significant difference in expression between female PS+R and female Control +R (Fig. 13). Interestingly, the selective down-regulation of Sodium/Potassium transporting protein ATPase alpha-1 subunit was observed in female PS $+\mathrm{R}$ compared to female Control $+\mathrm{R}$. There was no significant difference in expression of that protein in male PS+R compared to male Control +R (Fig. 14). In total, the proteomic data revealed an up-regulation of 24 proteins in male PS+R compared to male Control $\mathrm{R}$ (Table 1) that were mostly mitochondrial proteins involved in energy metabolism. The data 
also showed an up-regulation of 5 proteins and a down-regulation of 1 protein in female PS+R compared to female Control $+\mathrm{R}$ (Table 2).

Catecholamine concentrations were significantly different between male PS+R and male Control $+\mathrm{R}$ animals and between female $\mathrm{PS}+\mathrm{R}$ and female Control $+\mathrm{R}$ animals $(\mathrm{P}$ value $=$ 0.0112). The female PS $+\mathrm{R}$ had the highest level of norepinephrine while the male Control $+\mathrm{R}$ rats had the highest epinephrine levels.

These findings to indicate significant sex differences in response to prenatal stress that may influence myocardial function. Further studies are needed to determine the roles that these differences play in the changes in myocardial function that are seen in male PS+R and the potentially "protective” mechanisms in the female PS+R animals. 


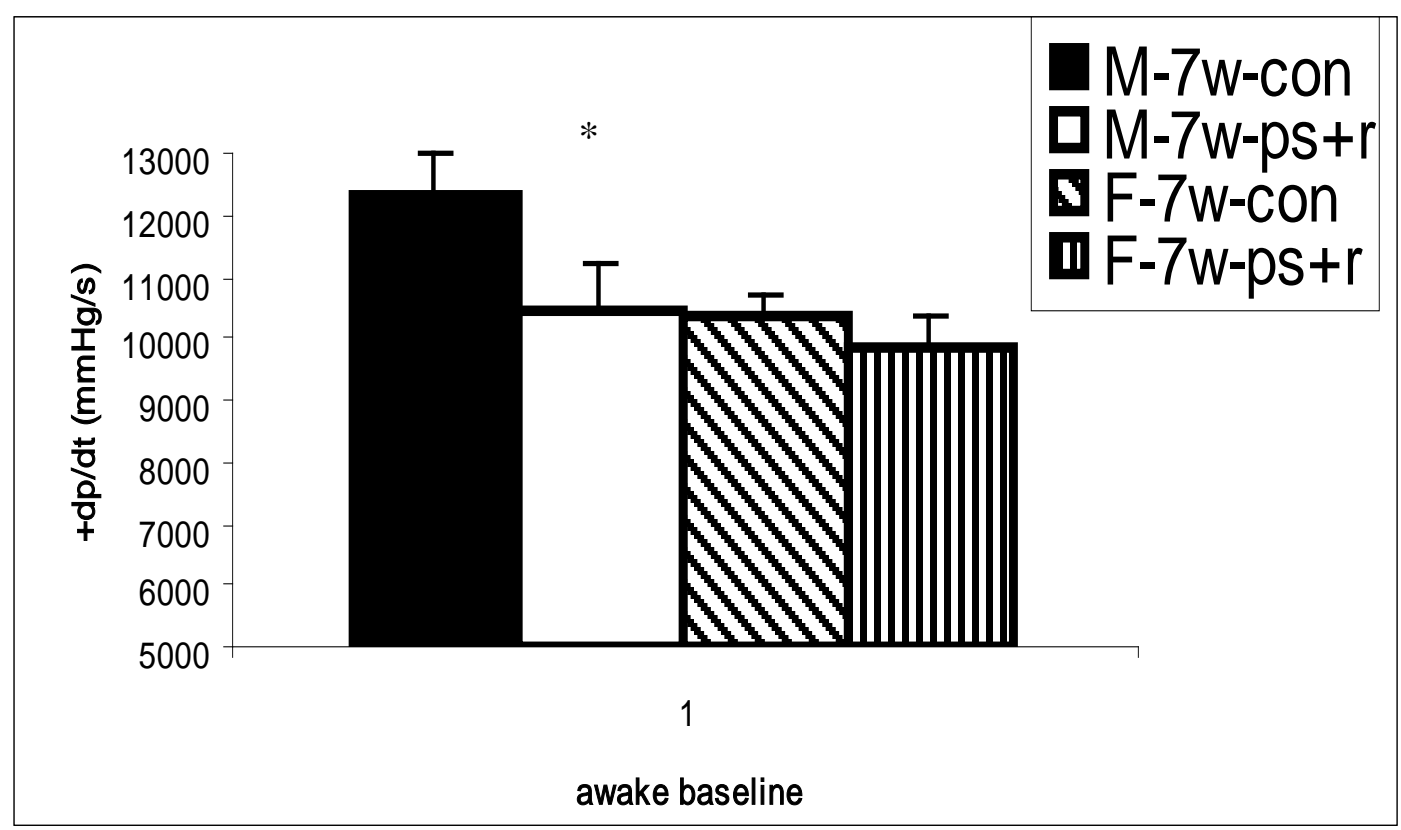

Figure 7. Bar graph depicting differences in hemodynamic responses between male vs. female rats after PS $+\mathrm{R}$. PS $+\mathrm{R}$ males demonstrated decreased systolic contractility compared with Control $+R$ males $(p<.05)$. Systolic function was not significantly different between $P S+R$ vs Control + R females. 


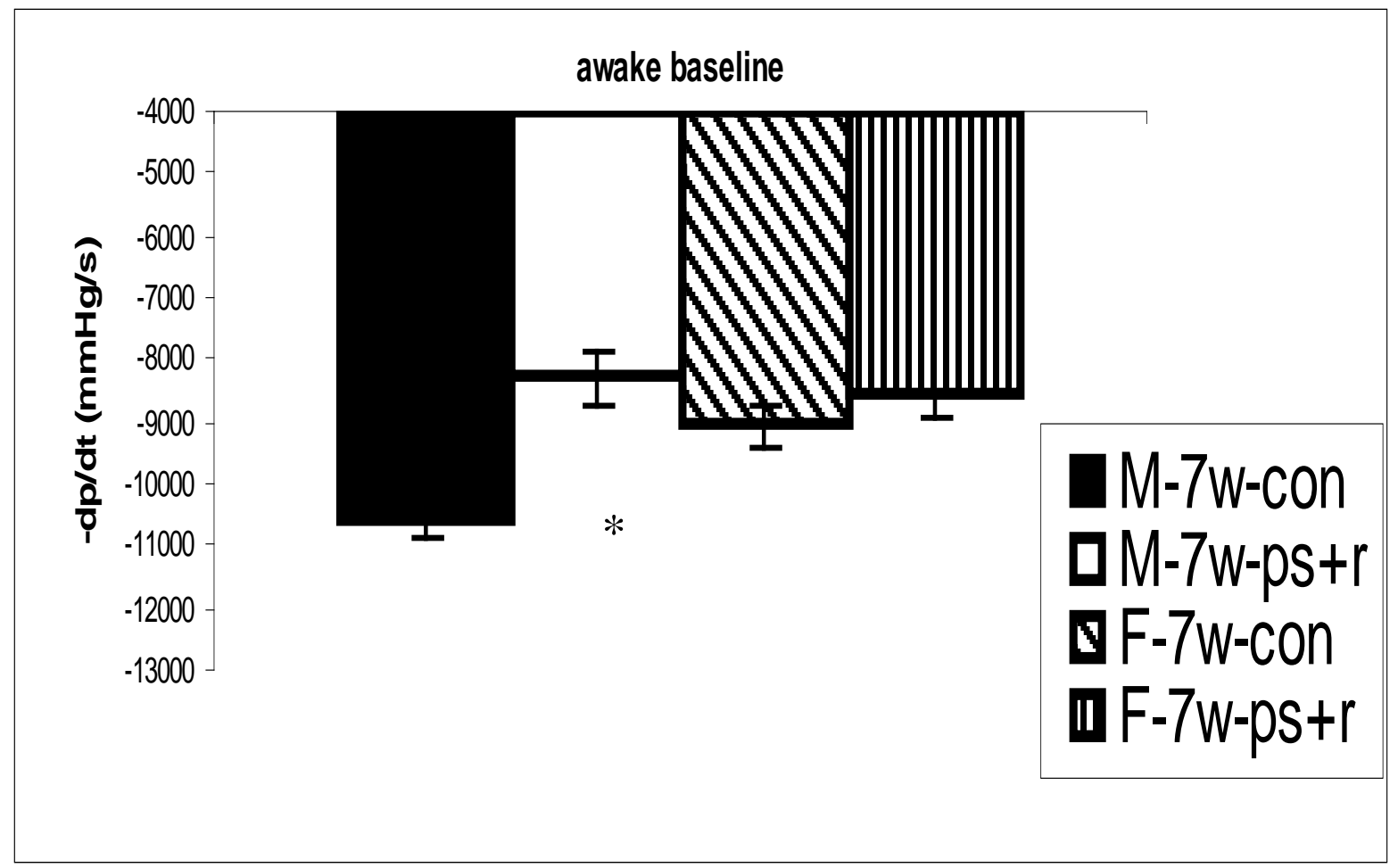

Figure 8. Bar graph depicting differences in hemodynamic responses between male vs. female rats after PS $+\mathrm{R}$. Diastolic dysfunction was significantly greater in male PS+R vs. male Control + $\mathrm{R}$ (Control $+\mathrm{R}$ vs. $\left.\mathrm{PS}+\mathrm{R},{ }^{*} \mathrm{P}<0.05\right)$. No differences between age-matched female $\mathrm{PS}+\mathrm{R}$ and female Control $+\mathrm{R}$ were observed. 


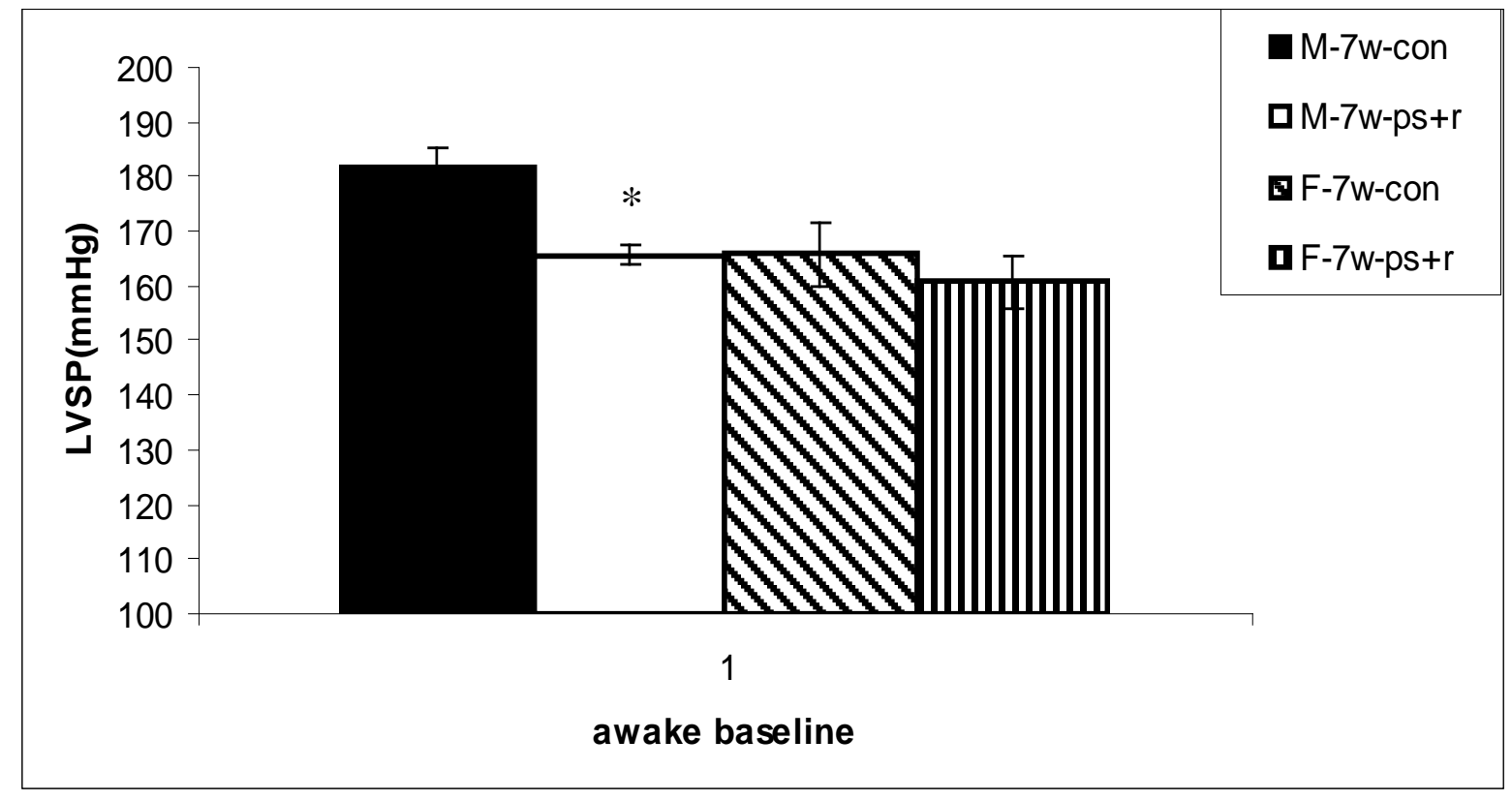

Figure 9. Bar graph depicting differences in left ventricular systolic pressure (LVSP) between male vs. female rats after PS+R. LVSP was significantly lower in male PS+R vs. male Control + $\mathrm{R}(\mathrm{p}<.05)$. However, no such differences between age-matched female PS+R and female Control $+\mathrm{R}$ were observed. 


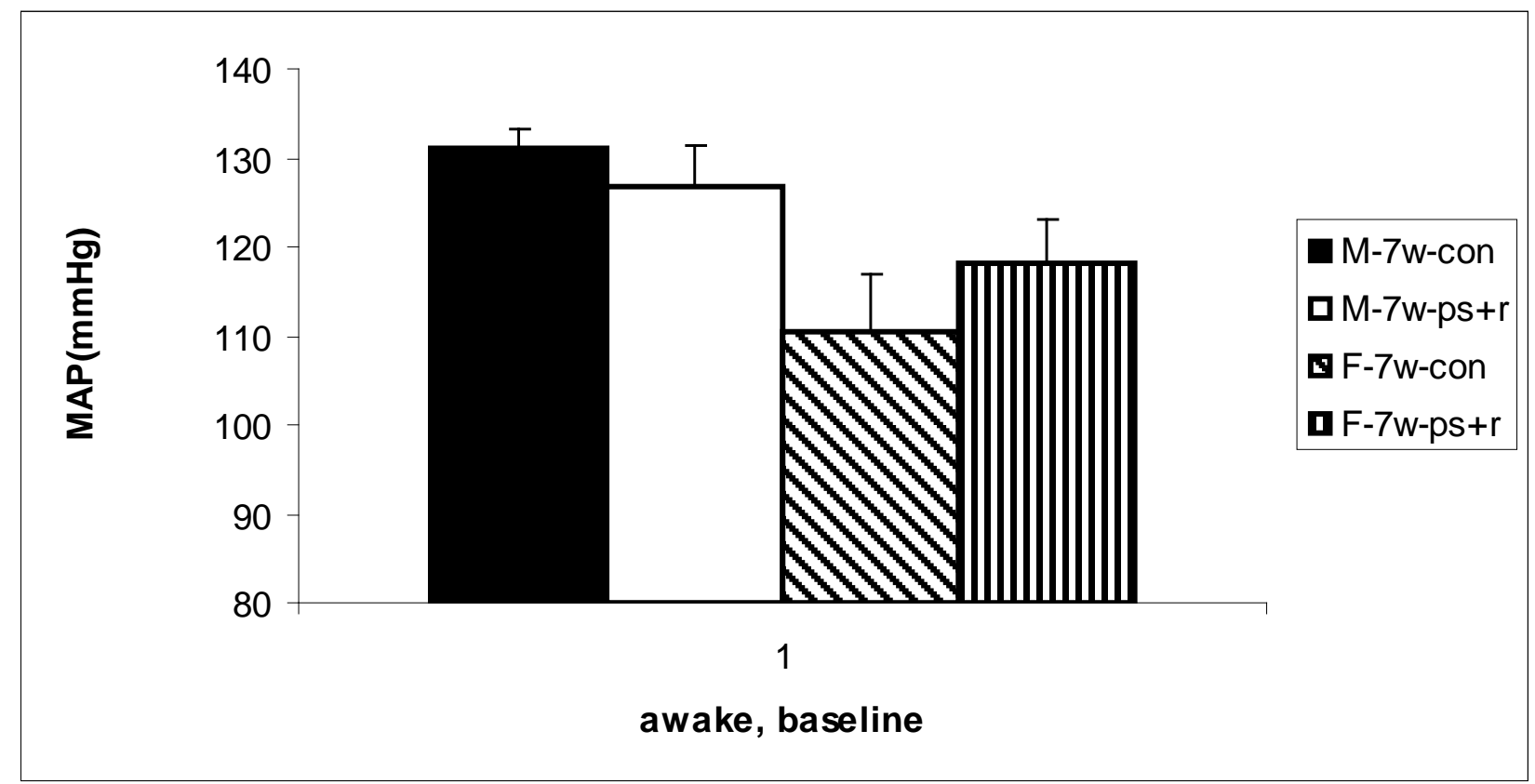

Figure 10. Bar graph depicting no differences in Mean Arterial Pressure (MAP) between male $\mathrm{PS}+\mathrm{R}$ and male Control $+\mathrm{R}$ or between female $\mathrm{PS}+\mathrm{R}$ and female Control $+\mathrm{R}$. 


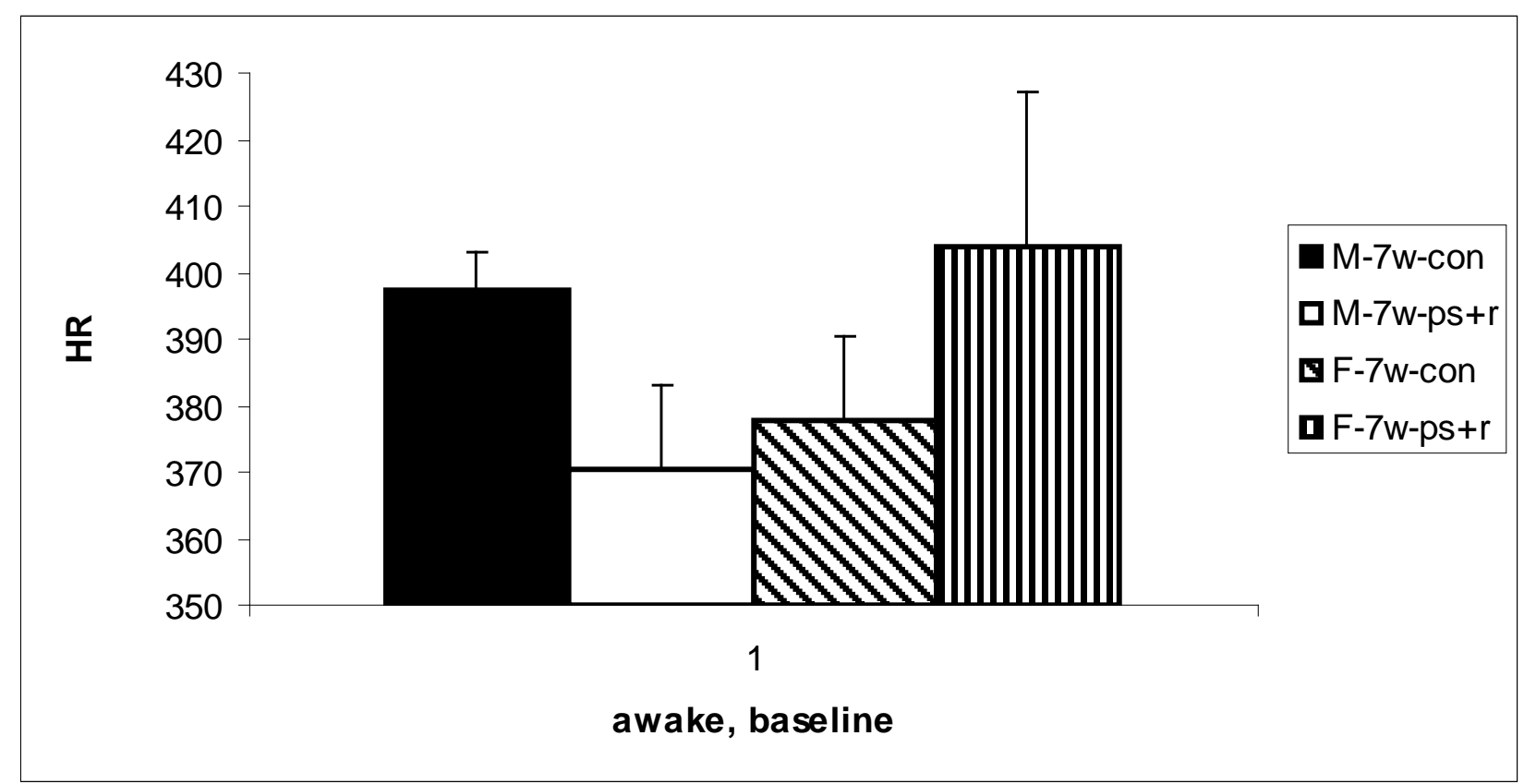

Figure 11. Bar graph depicting no differences in Heart Rate (HR) between male PS+R and male Control $+\mathrm{R}$ or between female $\mathrm{PS}+\mathrm{R}$ and female Control $+\mathrm{R}$. 


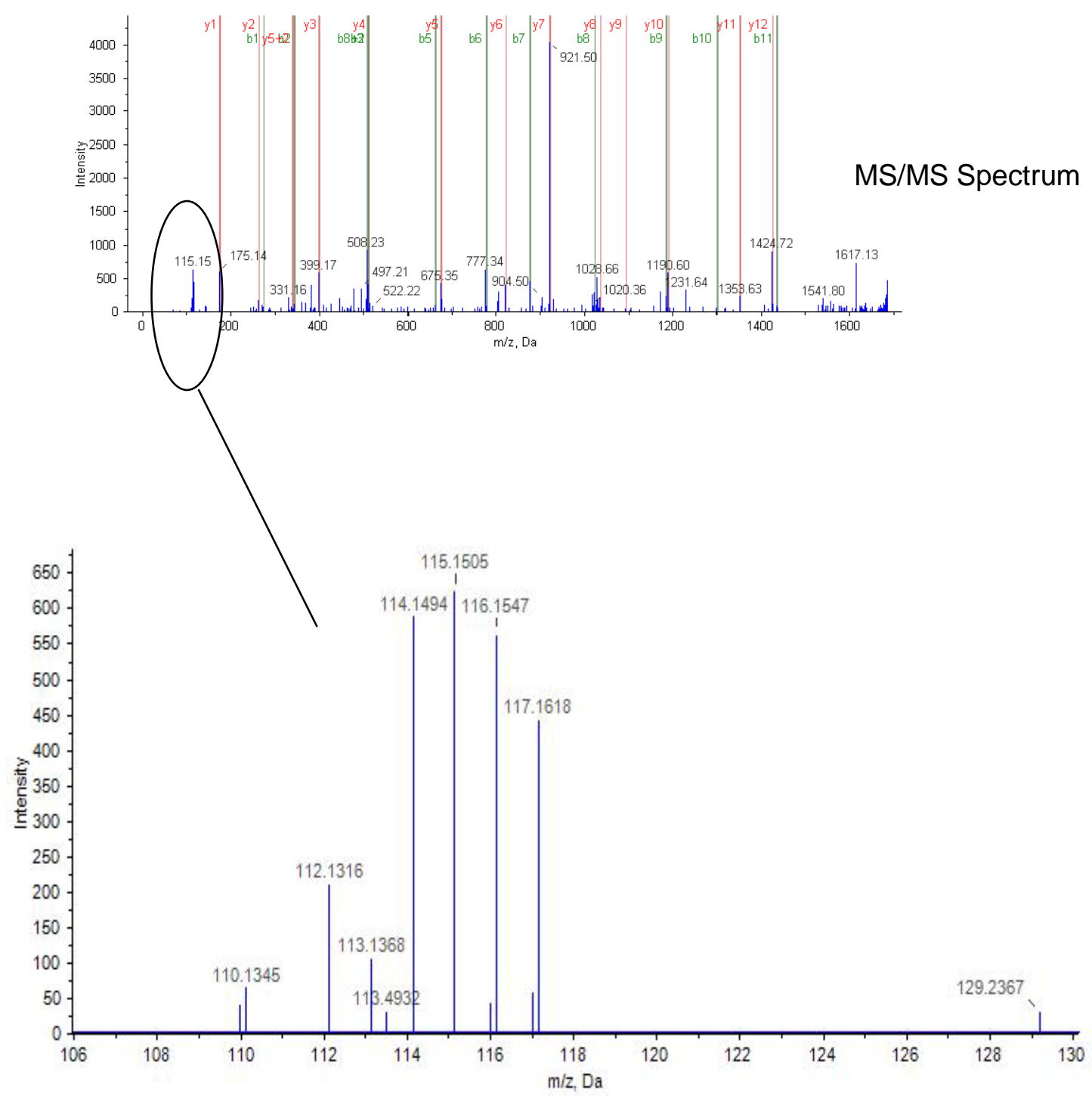

Figure 12. MS/MS spectrum depicting ATP Synthase Alpha subunit peptide that is upregulated in male PS+R (115) vs. male Control $+\mathrm{R}$ (117). However, there is no difference in expression in female PS+R (114) vs. female Control +R (116). 


\section{Cytochrome C oxidase subunit 4 peptide}

\section{VNPIQGFSAK[IT4]}

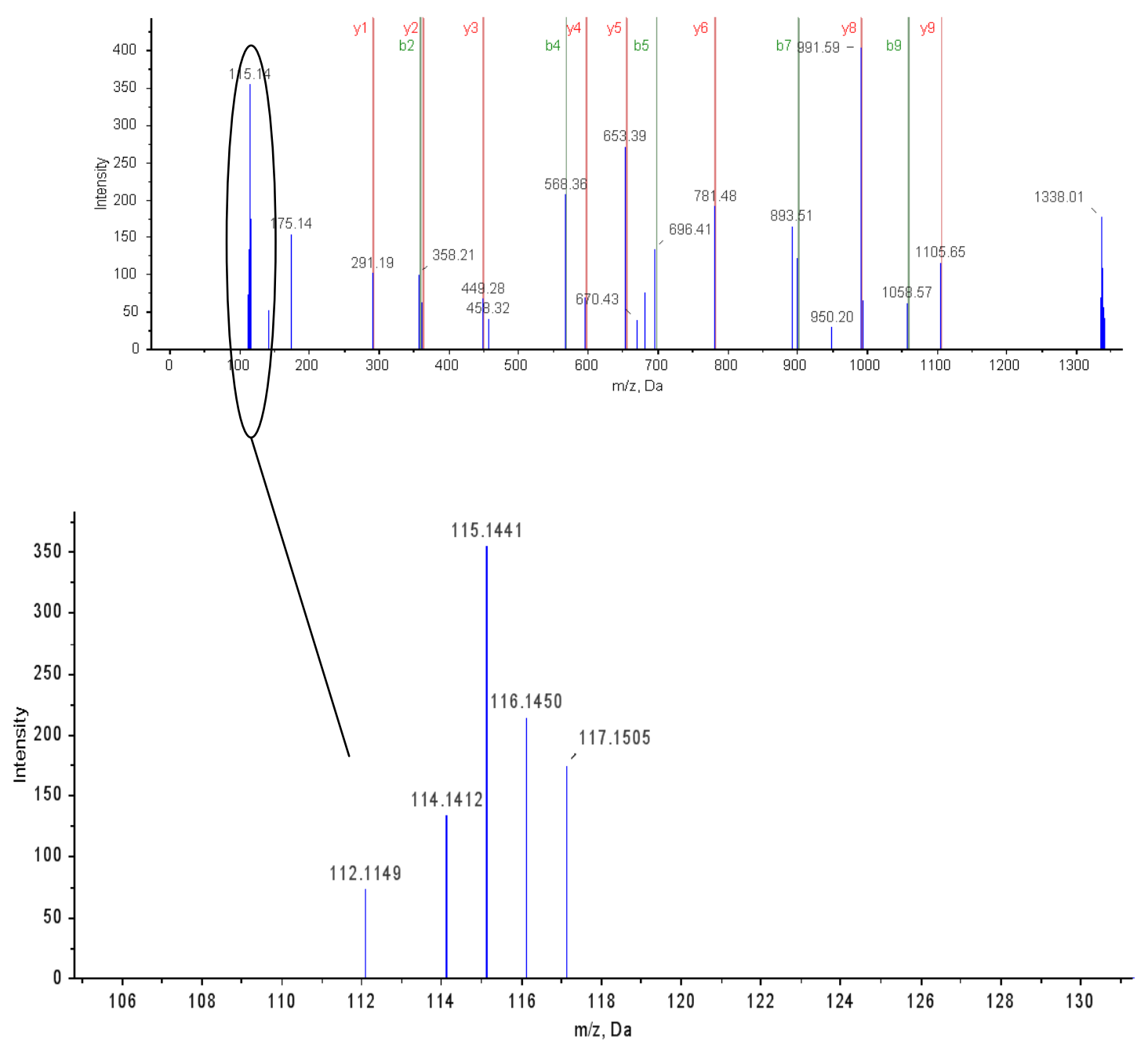

Figure 13. MS/MS spectrum depicting Cytochrome c oxidase subunit 4 peptide that is upregulated in male PS+R (115) vs. male Control +R (117). However, there is no difference in expression in female PS $+\mathrm{R}(114)$ vs. female Control $+\mathrm{R}(116)$. 
Sodium/Potassium transporting protein ATPase alpha-1 subunit LNIPVNQVNPR
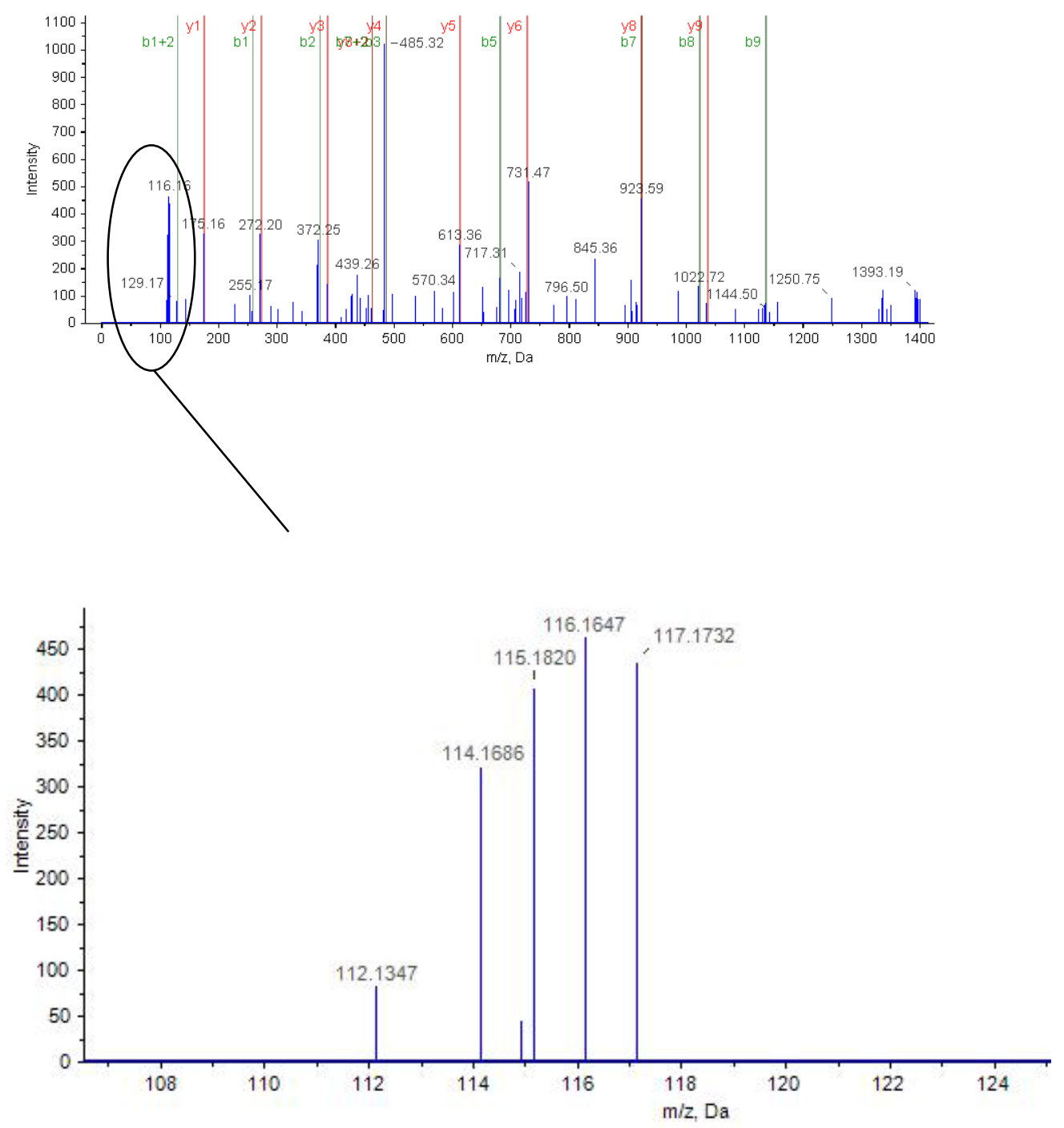

Figure 14. MS/MS spectrum depicting Sodium/potassium-transporting ATPase subunit alpha-1 peptide that is down-regulated in female PS+R (114) vs. female Control $+\mathrm{R}$ (116). However, there is no difference in expression between male $\mathrm{PS}+\mathrm{R}$ (115) vs male Control +R (117). 
Table 1. List of proteins that are up-regulated in male PS+R vs male Control $+\mathrm{R}$ (See legend below).

\begin{tabular}{|c|c|c|}
\hline Male PS+R vs. Male Control + R & $115: 117$ & P-Value 115:117 \\
\hline ATP synthase subunit beta, mitochondrial & 1.59364295 & 0.00748203 \\
\hline ATP synthase subunit alpha, mitochondrial & 1.40023303 & 0.000241715 \\
\hline Malate dehydrogenase, mitochondrial & 1.276039958 & 0.031488732 \\
\hline Aspartate aminotransferase, mitochondrial & 1.324023008 & 0.0360916 \\
\hline Creatine kinase S-type, mitochondrial & 1.294847965 & 0.041745812 \\
\hline $60 \mathrm{kDa}$ heat shock protein, mitochondrial & 1.384137988 & 0.01083641 \\
\hline Trifunctional enzyme subunit alpha, mitochondrial & 1.41494596 & 0.01479172 \\
\hline Tubulin beta- $2 \mathrm{C}$ chain & 1.349351048 & 0.026147399 \\
\hline Cytochrome b-c1 complex subunit 2, mitochondrial & 1.375763059 & 0.031450622 \\
\hline Cytochrome c oxidase subunit 5A, mitochondrial & 1.445060968 & 0.045742702 \\
\hline Creatine kinase M-type & 1.279070973 & 0.015846269 \\
\hline $\begin{array}{c}\text { Cytochrome c oxidase subunit } 4 \text { isoform 1, } \\
\text { mitochondrial }\end{array}$ & 1.428614974 & 0.005197079 \\
\hline $\begin{array}{c}\text { Dihydrolipoyllysine-residue succinyltransferase } \\
\text { component of 2-oxoglutarate dehydrogenase } \\
\text { complex, mitochondrial }\end{array}$ & 1.303359985 & 0.01797644 \\
\hline Trifunctional enzyme subunit beta, mitochondrial & 1.720718026 & 0.043290079 \\
\hline Stress-70 protein, mitochondrial & 1.427014947 & 0.026238089 \\
\hline Fatty acid-binding protein, heart & 1.811400056 & 0.028451569 \\
\hline Electron transfer flavoprotein subunit beta & 1.656386971 & 0.01491705 \\
\hline ATP synthase-coupling factor 6 , mitochondrial & 1.589025021 & 0.028148361 \\
\hline $\begin{array}{l}\text { Hydroxyacyl-coenzyme A dehydrogenase, } \\
\text { mitochondrial }\end{array}$ & 1.768646955 & 0.01304454 \\
\hline $10 \mathrm{kDa}$ heat shock protein, mitochondrial & 1.497455955 & 0.04435594 \\
\hline Glutamate dehydrogenase 1 , mitochondrial & 1.936133027 & 0.005710695 \\
\hline L-lactate dehydrogenase B chain & 1.414677978 & 0.001833215 \\
\hline Cytochrome b-c1 complex subunit 1 , mitochondrial & 1.677711964 & 0.02979501 \\
\hline Propionyl-CoA carboxylase beta chain, mitochondrial & 1.14547205 & 0.01812236 \\
\hline
\end{tabular}


Table 2. List of proteins that are up-regulated or downregulated in female PS+R vs. female Control $+\mathrm{R}$.

\begin{tabular}{|c|c|c|}
\hline iTRAQ color Key & P-Value & Descriptor \\
\hline & & \\
\hline$X X X$ & $<0.001$ & Ratio $<1=$ Downregulated \\
\hline$X X X$ & 0.001 to $<0.01$ & Ratio $<1=$ Downregulated \\
\hline$X X X$ & 0.01 to $<0.05$ & Ratio $<1=$ Downregulated \\
\hline$X X X$ & $>0.05$ & Any \\
\hline$X X X$ & 0.01 to $<0.05$ & Ratio $>1=$ upregulated \\
\hline$X X X$ & 0.001 to $<0.01$ & Ratio $>1=$ upregulated \\
\hline$X X X$ & $<0.001$ & Ratio $>1=$ upregulated \\
\hline
\end{tabular}

\begin{tabular}{|c|c|c|}
\hline $\begin{array}{c}\text { Female PS+R vS. Female } \\
\text { Control + R }\end{array}$ & $\mathbf{1 1 4 : 1 1 6}$ & P-Value 114:116 \\
\hline Creatine kinase S-type, mitochondrial & 1.308290005 & 0.034055032 \\
\hline Myoglobin & 1.498047948 & 0.004839128 \\
\hline $\begin{array}{c}\text { Phosphoglycerate kinase 1 } \\
\text { Cytochrome b-c1 complex subunit 1, } \\
\text { mitochondrial }\end{array}$ & 1.532250047 & 0.001759795 \\
\hline $\begin{array}{c}\text { Dihydrolipoyl dehydrogenase, } \\
\text { mitochondrial }\end{array}$ & 1.16941905 & 0.02739607 \\
\hline $\begin{array}{c}\text { Sodium/potassium-transporting ATPase } \\
\text { subunit alpha }\end{array}$ & 0.737179577 & 0.037929349 \\
\hline
\end{tabular}


Table 3. Norepinephrine measurements showing significant differences between male PS+R and male Control $+R$ and female $P S+R$ and female Control $+R(P$ value $=0.0112$ )

\begin{tabular}{|c|c|c|}
\hline Group & $\begin{array}{c}\text { pg/ml of } \\
\text { Norepinephrine }\end{array}$ & SEM \\
\hline Male Control +R & 341.6 & 67.4 \\
\hline Male PS+R & 232.9 & 43.3 \\
\hline Female Control +R & 236.4 & 44.6 \\
\hline Female PS+R & 458.2 & 51.5 \\
\hline
\end{tabular}


Table 4. Epinephrine measurements showing significant differences between male $\mathrm{PS}+\mathrm{R}$ and male Control $+R$ and female $P S+R$ and female Control $+R(P$ value $=0.0029)$.

\begin{tabular}{|c|c|c|}
\hline Group & pg/ ml of Epinephrine & SEM \\
\hline Male Control +R & 454.6 & 111.6 \\
\hline Male PS+R & 195.5 & 29.2 \\
\hline Female Control +R & 286.6 & 18.9 \\
\hline Female PS+R & 363.7 & 53.1 \\
\hline
\end{tabular}




\section{Discussion}

The results of this study confirm [our] previous reports that the combination of prenatal stress followed by restraint stress (PS+R) results in depressed systolic (+dP/dt and LVSP) and diastolic function (-dP/dt) in male PS+R when compared to male Control +R. However, there were no significant differences in systolic function, LVSP, or diastolic function between female PS $+\mathrm{R}$ and female Control $+\mathrm{R}$. These results support our preliminary data reported in a previous study of significant differences in hemodynamic responses between male and female PS+R (Chen et al.. 2009). The present study explored potential mechanisms responsible for these sex differences in myocardial response to prenatal stress.

Further mechanistic insights into the basis of the differences in the myocardial response to prenatal stress in males vs. females PS+R can be seen through proteomic analyses. A proteomics approach was taken as a screening tool to get a sense of the left ventricular myocardial protein differences between male and female PS+R compared to male and female Control $+\mathrm{R}$, respectively. Gene screening could identify a prohibitive number of functional, but unrelated genes that are different between males and females. Another advantage of proteomics over genetic approaches is that protein screening should preferentially identify translated proteins with identifiable functions.

Normal myocardial function depends on generating sufficient quantities of adenosine triphosphate (ATP) to meet the energy demands of the heart organ. These high demands for ATP can be met through the delivery of oxygen and oxidizable substrates to the cardiac myocyte. Many different metabolic pathways are involved in the generation of ATP. These pathways include glycolysis, $\beta$-oxidation, Krebs cycle, and oxidative phosphorylation. Creatine kinase is 
also important for the transfer of energy from mitochondria to myofibrils for contraction of the heart muscle (Carvajal, 2003). In heart muscle, energy reserves are not sufficient to sustain contractile function without the continuous flux of energy from these oxidizable substrates. On a dry weight basis, the heart has an ATP content of about $20 \mu \mathrm{mol} / \mathrm{g}$ and a myocardial O2 consumption rate of $5 \mathrm{mmol} / \mathrm{h} / \mathrm{g}$. At this rate of consumption, the heart turns over its entire ATP pool every 4-5 seconds (Depre, 2000).

Failure to generate the energy needed to carry out myocardial function results in mechanical failure of the heart (Neubauer, 2007). A variety of metabolic fuels can be used by the heart. These include fatty acids, glucose, lactate, ketones, and amino acids. Fatty acids are the preferred fuel, accounting for up to $90 \%$ of the total acetyl-CoA provided to the mitochondria of the cardiac myocyte (Giordano, 2005). There are three components of the metabolic machinery needed to supply the heart with energy. This includes the cellular uptake of free fatty acids and glucose from the diet and the breakdown of these components through beta-oxidation, glycolysis, and the entry of the intermediates into the citric acid cycle. The second component is the production of energy by the electron transport chain in the mitochondria. This is the site of production of ATP, which is the source of energy for all energy-consuming reactions in the heart. The third component of the metabolic machinery is ATP transfer and utilization. This requires creatine kinase to transport ATP to the myofibrils for heart muscle contraction (Neubauer, 2007). In the absence of oxygen, the energy produced by the previously described metabolic pathways is not sufficient to meet the needs of the cardiac muscle. The entry of acetyl-CoA into the citric acid cycle produces NADH and $\mathrm{FADH}_{2}$. The entry of these two cofactors into the electron transport chain generates ATP by oxidative phosphorylation in the mitochondria. Without sufficient oxygen, which serves as a terminal electron acceptor in the electron transport 
chain, electron transport ceases and the energy demands of the cardiac muscle are not met (Giordano, 2005).

Oxygen is very important for proper function of the cell. But, oxygen can have a toxic effect also. Oxidative stress is one way that oxygen can adversely affect proper myocardial function. There is a fine balance between the production of free radicals and the presence of a variety of endogenous antioxidants. A change in the equilibrium of these free radicals and antioxidants causes an increase in oxidative stress and initiates subcellular changes that could lead to cardiomyopathy and heart failure (Singal, 1998).

Oxygen is a diradical. This means that it has two electrons in its outermost shell. Because of this structural configuration, four electrons can be accepted by oxygen and may result in the formation of water, and the production of ATP. However, this same diradical configuration provides an ideal substrate for the production of free radicals. Singlet oxygen, superoxide radical, hydrogen peroxide, and hydroxyl radicals are all formed when the four electrons that can be accepted by oxygen are added one at a time. All of these compounds are highly unstable, extremely reactive, and have short half-lives. They are highly toxic to tissues such as the myocardium. This results in a decrease in high energy phosphates, loss of contractile function and may cause structural abnormalities. Free radicals affect the activity of the $\mathrm{Na}^{+} / \mathrm{K}^{+}$ ATPase, $\mathrm{Na}^{+} / \mathrm{Ca}^{2+}$ exchanger, and calcium binding, which may result in a decrease in calcium moving across the sarcolemma (Singal, 1998).

Many of the proteins that are up-regulated in the male PS+R rats compared to male Control $+\mathrm{R}$ rats are responsible for energy metabolism and ATP production. The utilization of carbohydrates and fatty acids has been shown to be influenced greatly by the rates of consumption and production of high energy compounds in cardiac muscle. Fatty acids have 
been identified as the preferred substrate by both in vivo and in vitro studies in the welloxygenated heart. Under conditions of increased energy utilization in the well-oxygenated heart, the consumption of fatty acids and glucose is accelerated. However, fatty acids are the preferred oxidative substrate. The restriction of oxygen availability accelerates glucose and glycogen utilization. In the male PS+R rat, there is an up-regulation of fatty acid-binding protein. Fatty acid binding protein (FABP) is found in the cytoplasm of the cardiac myocyte along with other tissues such as skeletal muscle, kidney, brain, and mammary glands. It is thought to play a role in the intracellular transport of long chain fatty acids and their acyl-CoA esters (Claffey, 1987). Trifunctional enzyme subunit alpha and trifunctional enzyme subunit beta are mitochondrial proteins found in the mitochondrial matrix. These proteins work in the pathways of lipid metabolism and fatty acid $\beta$-oxidation (Uchida, 1992). Hydroxyacyl-coenzyme A dehydrogenase is a mitochondrial matrix protein involved in lipid metabolism and fatty acid beta-oxidation. It plays an essential role in the beta-oxidation of short chain fatty acids (He, 1999).

Other examples of proteins used in energy metabolism and ATP production include malate dehydrogenase. It is a protein found in the mitochondrial matrix that catalyzes the conversion of malate to oxaloacetate in the citric acid cycle (Grant, 1986). Cytochrome b-c1 complex subunit 2 is a component of the ubiquinol-cytochrome c reductase complex (complex III or cytochrome b-c1 complex). This complex is a component of the mitochondrial respiratory chain, also known as the electron transport chain. This complex is the site of oxidative phosphorylation in the mitochondrial inner membrane. Cytochrome c oxidase subunit $5 \mathrm{~A}$ is the heme A-containing chain of cytochrome oxidase. It is also a part of the electron transport chain, along with cytochrome c oxidase subunit 4 isoform 1 . These are the terminal oxidases in mitochondrial electron transport (Schägger, 1995). 
Another important protein that was up-regulated in the male PS+R rat compared to the male Control $+\mathrm{R}$ rat is creatine kinase. Creatine kinase S-type and creatine kinase M-type are found in the mitochondria intermembrane. They catalyze the transfer of phosphate between ATP and various phosphogens such as creatine phosphate. The isoenzymes of creatine kinase play a central role in energy transduction in tissue with large, fluctuating demands such as skeletal muscle, heart, brain, and spermatozoa. Mitochondrial creatine kinase binds cardiolipin (Payne, 1991). Cardiolipin is almost exclusively located in the inner mitochondrial membrane (Houtkooper, 2008). Cardiolipin has been shown to play an important role in substrate transport in mitochondria. A decline in cardiolipin has been shown to decrease cytochrome c oxidase activity (Suh, 2001). Alterations in cardiolipin content or composition have been reported in diseases such as heart failure (Houtkooper, 2008).

An implication of increased ATP synthase is an increase in ATP production. ATP synthase subunit beta and ATP synthase subunit alpha are mitochondrial proteins that have two components, $\mathrm{F}(1)$ and $\mathrm{F}(0) . \mathrm{F}(1)$ contains the extramembraneous catalytic core and $\mathrm{F}(0)$ contains the membrane proton channel, linked together by a central stalk and a peripheral stalk. Mitochondrial membrane ATP synthases produce ATP from ADP in the presence of a proton gradient across the membrane. This gradient is generated by electron transport complexes of the respiratory chain (Futai, 1983).

Other proteins that are up-regulated in the male PS+R compared to the male Control $+\mathrm{R}$ rats include aspartate aminotransferase. This mitochondrial matrix protein plays a key role in amino acid metabolism. It is located in the mitochondria of liver, pancreas, spleen, heart, pituitary gland and submandibular gland cells. This protein is important for metabolite exchange between the mitochondria and cytosol. It also facilitates the cellular uptake of long-chain free 
fatty acids. The catalytic function of this protein includes the production of oxaloacetate and glutamate from aspartate and 2-oxogluterate (Mattingly et al., 1987),

Oxidative stress can produce multiple changes in a cell that can ultimately affect protein structures and function. The heat shock proteins act as molecular chaperones, and either degrade or repair damaged proteins as a defense strategy to ensure survival. Myocardial ischemia is one physiological stressor that produces a pathologic state in which protein damage and misfolding are a common result (Benjamin, 1998). Stress-70 protein, $60 \mathrm{kDa}$ heat shock protein, and 10 $\mathrm{kDa}$ heat shock protein are found in the mitochondrial matrix. Stress -70 protein belongs to the heat shock protein 70 family and is implicated in the control of cell proliferation and cellular aging. It also may act as a chaperone (Webster, 1994). This particular heat shock protein has been shown to be cardioprotective (Knowlton, 1995). The $60 \mathrm{kDa}$ heat shock protein is implicated in mitochondrial protein import and macromolecular assembly. Under normal conditions, this protein may facilitate correct folding of imported proteins. Under stress conditions, it may prevent the misfolding and promote the refolding and proper assembly of unfolded polypeptides that may be generated (Kim et al., 2009). The $10 \mathrm{kDa}$ heat shock protein expression is induced by stress, and works together with other proteins and suppresses ATPase activity. Like stress-70 protein, it may act as a chaperone (Hartman, 1992). By acting as chaperones, heat shock proteins facilitate the transport of macromolecules across membranes by unfolding and refolding the macromolecules as they pass through the membranes. Heat shock proteins constitute an important endogenous intracellular protective system (Knowlton, 1995).

Tubulin is a protein that is a major component of microtubules and binds GTP. The highly acidic C-terminal region of this protein may bind cations such as calcium (Gerhard, 2004). A study by Kostin et al. (2000) showed that an increase in tubulin was correlated with increased 
left ventricular diastolic dysfunction due to the increase in left ventricular stiffness. The upregulation of this protein in male PS+R rats could contribute to the diastolic dysfunction our laboratory observed in the male PS+R rats compared to the male Control $+\mathrm{R}$ rats.

Dihydrolipoyllysine-residue succinytransferase is a component of the 2-oxoglutarate dehydrogenase complex. The 2-oxoglutarate dehydrogenase complex catalyzes the overall conversion of 2-oxoglutarate to succinyl-CoA and $\mathrm{CO}_{2}$. It is located in the mitochondrion and is involved in amino acid degradation (Nakano, 1991).

Electron transfer flavoprotein subunit beta is a protein found in the mitochondrial matrix and is a specific electron acceptor for several dehydrogenases, including five acyl-CoA dehydrogenases. The electrons are transferred to the main mitochondrial electron transport chain via ETF-ubiquinone oxidoreductase (ETF dehydrogenase) (Gerhard et al., 2004).

Glutamate dehydrogenase 1 is widely expressed throughout the hippocampus and may be involved in learning and memory reactions by increasing the turnover of the excitatory neurotransmitter glutamate. It is contained within the mitochondrion matrix (Das et al., 1993).

L-lactate dehydrogenase B chain is involved in the fermentation of pyruvate to lactate. It is contained within the cytoplasm of the cell (Tsuji et al., 1994).

Proteomic analyses of female PS $+\mathrm{R}$ rats compared to the female Control $+\mathrm{R}$ rats provide a sharp contrast to the male PS+R compared with the male Control $+\mathrm{R}$. Only four proteins were up-regulated and one protein that is down-regulated. The up-regulated proteins include Propionyl-CoA carboxylase beta chain, which is found in the mitochondrial matrix. It is involved in the conversion of propanoyl-CoA to methylmalonyl-CoA (Kraus et al., 1986).

Phosphoglycerate kinase 1 is a cytoplasmic protein that is also up-regulated in female PS+R. It is involved in carbohydrate degradation, glycolysis, and the production of pyruvate from 
glyceraldehyde 30-phosphate (Ciccarese et al., 1989). Dihydrolipoyl dehydrogenase is a mitochondrial matrix protein that also was up-regulated in female PS+R compared with female Control+R. This protein is a component of the glycine cleavage system as well as the alphaketoacid dehydrogenase complexes (Gerhard et al., 2004).

One very important protein that was up-regulated in the female PS+R compared to the female Control $+\mathrm{R}$ is myoglobin. Myoglobin is a protein found in the cytoplasm of cells. It serves as a reserve supply of oxygen and facilitates the movement of oxygen within muscles such as the heart (Gerhard et al., 2004). Flögel et al. (2004) showed the attenuation of oxidative stress by myoglobin in cardiac muscle in vivo. This function is particularly important to protect against oxidant injury during the early reperfusion period after an incident of ischemia.

The one protein that was down-regulated in the female PS $+\mathrm{R}$ compared to the Control $+\mathrm{R}$ rats was the sodium/potassium ATPase. Sodium/potassium ATPase subunit alpha 1 is a multipass membrane protein contained within the membrane of cells. Subunit alpha 1 is the catalytic component of the active enzyme, which catalyzes the hydrolysis of ATP coupled with the exchange of sodium and potassium ions across the plasma membrane. This provides the energy for active transport of various nutrients. The phosphorylation on Tyr-10 modulates the pumping activity (Feschenko and Sweadner, 1995). Cardiac glycosides are known to bind to and inhibit the cardiac myocyte sodium/potassium ATPase. The pharmacodynamic properties of digitalis glycosides include a direct positive inotropic effect on cardiac muscle and an indirect slowing of the heart rate (Doherty and Kane, 1975). The down-regulation of the sodium/potassium ATPase should be similar to the effect of adding digitalis glycosides. The cardiac myocytes would retain more sodium. This sodium could then be used in the sodium/calcium exchanger (NCX). The NCX removes one calcium ion in exchange for three sodium ions. Due to the increase in sodium 
in the cardiac myocyte in which sodium/potassium ATPase is down-regulated, there would also be an increase in calcium that can be used for heart muscle contraction (Philipson and Nicoll, 2000).

Catecholamine concentrations for PS+R males and females were expected to be increased due to the stress to which they had been exposed. However, male PS+R norepinephrine and epinephrine concentrations were decreased compared to male Control $+\mathrm{R}$. Female PS+R norepinephrine and epinephrine concentrations were increased significantly compared to female Control $+\mathrm{R}$. Other stress studies have shown an increase in catecholamines in PS animals exposed to stress. Here, we can see another difference in the male and female response to prenatal stress followed by restraint stress. This may be due to the timing of our blood collections. Our blood collection occurred the day after the last restraint while other studies showed an increase in catecholamines when blood was drawn the same day as the stress (Weinstock, 1998). The lower catecholamines in male PS+R may also be due to permanent hormonally induced changes. These changes may contribute to the feminization of these males, as well as making their catecholamine concentrations more like those of the female Control $+R$ animals (Moyer et al., 1978).

These data demonstrated a sex difference in the myocardial response to prenatal stress. As seen by the hemodynamic data, the male PS+R demonstrated myocardial dysfunction compared to male Control $+\mathrm{R}$. On the other hand, Female PS $+\mathrm{R}$ did not demonstrate a similar profile. The proteomics data were interpreted to indicate that the male PS+R experienced enhanced oxidative stress, possibly due to an effort to increase ATP production. Alternatively, the up-regulation of mitochondrial enzymes and heat shock proteins reflected an attempt at an adaptive response to oxidative stress. 
The proteomic data in the female PS+R demonstrated a very different profile. The upregulation of myoglobin and the down-regulation of the sodium/potassium ATPase should enhance intracellular oxygen and calcium availability for myocardial contraction. Further study is required to determine the potential survival advantages and disadvantages conferred by each of these two very different proteomic profiles. 


\section{Literature Cited}

Adams, Jr. K.F., C.A. Sueta, M. Gheorghiade, C.M. O’Connor, T.A. Schwartz, G.G. Koch, B. Uretsky, K. Swedberg, W. McKenna, J. Soler-Soler, and R.M. Califf. 1999. Gender differences in survival in advanced Heart Failure. Circulation. 99:1816-1821.

Bae, S., and L. Zhang. 2005. Gender differences in cardioprotection against ischemia/reperfusion injury in adult rat hearts: Focus on Akt and Protein Kinase C signaling. The Journal of Pharmacology and Experimental Therapeutics. 315:1125-1135.

Benjamin, I.J., and D.R. McMillan. 1998. Stress (heat shock) proteins: Molecular chaperones in cardiovascular biology and disease. Circulation Research. 83:117-132.

Bowman, R.E., N.J. Maclusky, Y. Sarmiento, M. Frankfurt, M. Gordon, and V.N. Luine. 2004. Sexually dimorphic effects of prenatal stress on cognition, hormonal responses, and central neurotransmitters. Endocrinology. 145(8):3778-3787.

Braastad, B.O. 1998. Effects of prenatal stress on behaviour of offspring of laboratory and farmed mammals. Applied Animal Behaviour Science. 61:159-180.

Braunwald E. and R.A. Kloner. 1982. The stunned myocardium: Prolonged, postischemic ventricular dysfunction. Circulation. 66:1146-1149.

Carvajal, K., and R. Moreno-Sánchez. 2003. Heart metabolic disturbances in cardiovascular disease. Archives of Medical Research. 34:89-99.

Chen, F., H. Kan, G. Hobbs, and M.S. Finkel. 2009. p38 MAP kinase inhibitor reverses stressinduced myocardial dysfunction in vivo. Journal of Applied Physiology. 106:1132-1141.

Ciccarese, S., S. Tommasi, and G. Vonghia. 1989. Cloning and cDNA sequence of the rat Xchromosome linked phosphoglycerate kinase. Biochemical and Biophysical Research Communications. 165(3):1337-1344.

Claffey, K.P., V.L. Herrera, P. Brecher, and N. Ruiz-Opazo. 1987. Cloning and tissue distribution of rat heart fatty acid binding protein mRNA: identical forms in heart and skeletal muscle. Biochemistry. 26(24):7900-7904.

Cratty M.S., H.E. Ward, E.A. Johnson, A.J. Azzaro, and D.L. Birkle. 1995. Prenatal stress increases corticotropin-releasing factor (CRF) content and release in rat amygdala minces. Brain Res. 675: 297-302.

Das, A.T. A.C. Arnberg, H. Malingre, P. Moerer, R. Charles, A.F.M. Moorman, and W.H. Lamers. 1993. Isolation and characterization of the rat gene encoding glutamate dehydrogenase. European Journal of Biochemistry. 211:795-803. 
Depre, C., and H. Taegtmeyer. 2000. Metabolic aspects of programmed cell survival and cell death in the heart. Cardiovascular Research. 45:538-548.

Doherty, J.E., and J.J. Kane. 1975. Clinical pharmacology of digitalis glycosides. Annual Review of Medicine. 26:159-171.

Feschenko, M.S., and K.J. Sweadner. 1995. Structural basis for species-specific differences in the phosphorylation of Na,K-ATPase by Protein Kinase C. The Journal of Biological Chemistry. 270(23):14072-14077.

Flögel, U., A. Gödecke, L. Klotz, and J. Schrader. 2004. Role of myoglobin in the antioxidant defense of the heart. The FASEB Journal. Express article:1-22.

Fride E., Y. Dan, J. Feldon, G. Halevy, and M. Weinstock. 1986. Effects of prenatal stress on vulnerability to stress in prepubertal and adult rats. Physiol.Behav. 37: 681-687.

Fride, E., M. Weinstock. 1988. Prenatal stress increases anxiety-related behavior and alters cerebral lateralization of dopamine activity. Life Sci. 42: 1059-1065.

Futai, M., and H. Kanazawa. 1983. Structure and function of proton-translocating adenosine triphosphatase (F0F1): Biochemical and molecular biological approaches. Microbiological Reviews. 47(3):285-312.

Gerhard, D.S., L. Wagner, E.A. Feingold, C.M. Shenmen, L.H. Grouse, G. Schuler, S.L. Klein, S. Old, R. Rasooly, P. Good, et. al. 2004. The status, quality, and expansion of the NIH fulllength cDNA project: the Mammalian Gene Collection (MGC). Genome Research. 14(10B):2121-2127.

Giordano, F.J. 2005. The role of oxygen in myocardial energetics and metabolism. Journal of Clinical Investigation. 115(3):500-508.

Grant, P.M., J. Tellam, V.L. May, and A.W. Strauss. 1986. Isolation and nucleotide sequence of a cDNA clone encoding rat mitochondrial malate dehydrogenase. Nucleic Acids Research. 14(15):6053-6066.

Hartman, D.J., N.J. Hoogenraad, R. Condron, and P.B. Høj. 1992. Identification of a mammalian $10-\mathrm{kDa}$ heat shock protein, a mitochondrial chaperonin 10 homologue essential for assisted folding of trimeric ornithine transcarbamoylase in vitro. Proceeding of the National Academy of Science. 89(8):3394-3398.

He, X.Y., G. Zhang, F. Biecha, and S.Y. Yang. 1999. Identity of heart and liver L-3-hydroxyacyl coenzyme A dehydrogenase. Biochimica et Biophysica Actc. 1437(2):119-123. 
Heyndrickx G.R., R.W. Millard, R.J. McRitchie, P.R. Maroko, and S.F. Vatner. 1975. Regional myocardial functional and electrophysiological alterations after brief coronary artery occlusion in conscious dogs. J Clin Invest 56(4):978-85

Huse, J.M., and D.P. Kelly. 2005. Mitochondrial energy metabolism in heart failure” a question of balance. The Journal of Clinical Investigation. 115(3):547-555.

Kan H, M.S. Finkel. 2001. Interactions between cytokines and neurohormonal systems in the failing heart. Heart Failure Reviews 6:119-127.

Kan, H., D. Birkle, A.C. Jain, C. Failinger, S. Xie, and M.S. Finkel. 2005. p38 MAP kinase inhibitor reverses stress-induced cardiac myocyte dysfunction. Journal of Applied Physiology. 98:77-82.

Kan, H., M.S. Finkel. 2003. Inflammatory mediators and reversible myocardial dysfunction. Journal of Cellular Physiology. 195:1-11.

Kim, S.C., J.P. Stice, L. Chen, J.S. Jung, S. Gupta, Y. Wang, G. Baumgarten, J. Trial, and A.A. Knowlton. 2009. Extracellular heat shock protein 60, cardiac myocytes, and apoptosis. Circulation Research. 105(2):1186-1195.

Knowlton, et. al. 1995. The role of heat shock proteins in the heart. Journal of Molecular and Cellular Cardiology. 27(1):121-131.

Kostin, S., S. Hein, E. Arnon, D. Scholz, and J. Schaper. 2000. The cytoskeleton and related proteins in the human failing heart. Heart Failure Reviews. 5:271-280.

Kraus, J.P., F. Firgaira, J. Novotny, F. Kalousek, K.R. Williams, C. Williamson, T. Ohura, and L.E. Rosenberg. 1986. Coding sequence of the precursor of the $\beta$ subunit of rat propionylCoA carboxylase. Proceedings of the National Academy of Sciences. 83:8049-8053.

Lay, D.C, Jr., H.G. Kattesh, J.E. Cunnick, M.J., Daniels, K.A. McMunn, M.J. Toscano, and M.P. Roberts. 2008. Prenatal stress effects on pig development and response to weaning. Journal of Animal Science. 86:1316-1324.

Mattingly Jr., J.R., F.J. Rodriguez-Berrocal, J. Gordon, A. Iriarte, and M. Marinez-Carrion. 1987. Molecular cloning and in vivo expression of a precursor to rat mitochondrial aspartate aminotransferase. Biochemistry Biophysical Research Communications. 149(3):859-865.

McCormick, C.M., J.W. Smythe, S. Sharma, and M.J. Meaney. 1995. Sex-specific effects of prenatal stress on hypothalamic-pituitary-adrenal responses to stress and brain glucocorticoid receptor density. Developmental Brain Research. 84:55-61.

Moyer, J.A., L.R. Herrenkohl, and D.M. Jacobowitz. 1978. Stress during pregnancy. Effect on catecholamines in discrete brain regions of offspring as adults. Brain Research. 144(1):173-178. 
Mulder, E.J.H., P.G. Robles de Medina, A.C. Huizink, B.R.H. Van den Bergh, J.K. Buitelaar, and G.H.A. Visser. 2002. Prenatal maternal stress: effects on pregnancy and the (unborn) child. Early Human Development. 70:3-14.

Nakano, K., S. Matuda, T. Yamanaka, H. Tsubouchi, S. Nakagawa, K. Titani, S. Ohta, and T. Miyata. 1991. Purification and molecular cloning of succinyltransferase of the rat $\alpha$ Ketoglutarate dehydrogenase complex. The Journal of Biological Chemistry. 266(28):19013-19017.

Neely, J.R., and H.E. Morgan. 1974. Relationship between carbohydrate and lipid metabolism and the energy balance of heart muscle. Annual Review of Physiology. 36:413-459.

Neubauer, S. 2007. The failing heart - An engine out of fuel. New England Journal of Medicine. 356:1140-1151.

Nishio, H., S. Kasuga, M. Ushijima, and Y. Harada. 2001. Prenatal stress and postnatal development of neonatal rats- sex-dependent effects on emotional behavior and learning ability of neonatal rats. International Journal of Developmental Neuroscience. 19(1): 3745.

Payne, R.M., R.C. Haas, and A.W. Strauss. 1991. Structural characterization and tissue-specific expression of the mRNAs encoding isoenzymes from two rat mitochondrial creatine kinase genes. Biochimica et Biophysica Acta. 1089(3):352-361.

Philipson, K.D., and D.A. Nicoll. 2000. Sodium-Calcium exchange: A molecular perspective. Annual Review of Physiology. 62:111-133.

Schägger, H., H. Noack, W. Halangk, U. Brandt, and G. Von Jagow. 1995. Cytochrome-c oxidase in developing rat heart. Enzymic properties and amino-terminal sequences suggest identity of the fetal heart and the adult liver isoform. European Journal of Biochemistry. 230:235-241.

Schaible, T.F., and J. Scheuer. 1984. Comparison of heart function in male and female rats. Basic Research in Cardiology. 79(4):402-412.

Singal, P.K., N. Khaper, V. Palace, and D. Kumar. 1998. The role of oxidative stress in the genesis of heart disease. Cardiovascular Research. 40:426-432.

Stanley, W.C., F.A. Recchia, and G.D. Lopaschuk. 2005. Myocardial substrate metabolism in the normal and failing heart. Physiological Reviews. 85:1093-1129.

Takahashi L.K., N.H., Kalin, C.M. Barksdale, J.A. Vanden Burgt, and M.S. Brownfield. 1988. Stressor controllability during pregnancy influences pituitary-adrenal hormone concentrations and analgesic responsiveness in offspring. Physiol.Behav. 42: 323-329. 
Takahashi L.K., E.W. Baker, and N.H. Kalin. 1990 Ontogeny of behavioral and hormonal responses to stress in prenatally stressed male rat pups. Physiol.Behav. 47: 357-364.

Tsuji, S., M.A. Qureshi, E.W. Hou, W.M. Fitch, and S.S.-L. Li. 1994. Evolutionary relationships of lactate dehydrogenases (LDHs) from mammals, birds, and amphibian, fish, barley, and bacteria: LDH cDNA sequences from Xenopus, pig and rat. Proceedings of the National Academy of Sciences. 91:9392-9396.

Uchida, Y., K. Izai, T. Orii, and T. Hashimoto. 1992. Novel fatty acid beta-ooxidation enzymes in rat liver mitochondria. II. Purification and properties of enoyl-coenzyme A (CoA) hydratase/3-ydroxyacyl-CoA dehydrogenase/3-ketoacyl-CoA thiolase trifunctional protein. Journal of Biological Chemistry. 267(2):1034-1041.

Ward, H.E., E.A. Johnson, A.K. Salm, D.L. Birkle. 2000. Effects of prenatal stress on defensive withdrawal behavior and corticotrophin releasing factor systems in rat brain. Physiology and Behavior. 70:359-366.

Webster, T.J., D. J. Naylor, D.J. Hartman, P.B. Høj, and N.J. Hoogenraad. 1994. cDNA cloning and efficient mitochondrial import of pre-mtHSP70 from rat liver. DNA Cell Biology. 13(12):1213-1230.

Weinstock, M. 1997. Does prenatal stress impair coping and regulation of hypothalamicpituitary-adrenal axis? Neurosci.Biobehav.Rev. 21: 1-10.

Weinstock M., T. Poltyrev. D. Schorer-Apelbaum, D. Men, and R. Mccarty. 1998. Effect of prenatal stress on plasma corticosterone and catecholamines in response to footshook in rats. Physiol.Behav. 64: 439-444.

Weinstock, M. 2007. Gender differences in the effects of prenatal stress on brain development and behaviour. Neurochemical Research. 32:1730-1740. 